Working Paper/Document de travail 2013-22

\title{
The Threat of Counterfeiting in Competitive Search Equilibrium
}

by Enchuan Shao 
Bank of Canada Working Paper 2013-22

July 2013

\title{
The Threat of Counterfeiting in Competitive Search Equilibrium
}

\author{
by \\ Enchuan Shao \\ Currency Department \\ Bank of Canada \\ Ottawa, Ontario, Canada K1A OG9 \\ eshao@bankofcanada.ca
}

Bank of Canada working papers are theoretical or empirical works-in-progress on subjects in economics and finance. The views expressed in this paper are those of the author.

No responsibility for them should be attributed to the Bank of Canada. 


\section{Acknowledgements}

I would like to thank Jonathan Chiu, Ben Fung, Janet Jiang, Gerald Stuber, and Russell

Wong for their comments and useful discussions. I would also like to thank Glen Keenleyside for his excellent editorial assistance. 


\begin{abstract}
Recent studies in monetary theory show that if buyers can use lotteries to signal the quality of bank notes, counterfeiting does not occur in a pooling equilibrium. In this paper, I investigate the robustness of this non-existence result by considering an alternative trading mechanism. Specifically, a competitive search environment is employed in which sellers post offers and buyers direct their search based on those offers. In contrast to the previous studies, buyers' ability to signal is fully eliminated in this environment. However, I find that counterfeiting does not exist if the equilibrium concept proposed by Guerrieri et al. (2010) is used. This is a refinement scheme in which sellers' out-of-equilibrium beliefs about the likelihood of meeting with different types of buyers are restricted. Moreover, a threat of counterfeiting can result in the collapse of a monetary equilibrium. An extension of the model is provided which allows the threat of counterfeiting to materialize, in that some buyers cannot observe the offers, and therefore search randomly. Counterfeit notes are produced by those buyers who randomly search.
\end{abstract}

JEL classification: D82, D83, E42

Bank classification: Bank notes

\title{
Résumé
}

Les récentes études en théorie monétaire ont montré que, si les indications des acheteurs sur la qualité des billets de banque sont obtenues au moyen de loteries, la contrefaçon n'existe pas en situation d'équilibre non séparateur. L'auteur fait appel ici à un autre mécanisme de négociation pour vérifier la robustesse de ce résultat. Il définit un cadre de prospection concurrentielle dans lequel les vendeurs affichent des offres qui aiguillent les acheteurs. Il est impossible à ces derniers de transmettre des signaux, hypothèse différente de celle retenue dans les travaux précédents. L’auteur conclut que, malgré cela, la contrefaçon n'existe pas en situation d'équilibre si l'équilibre est défini à la manière de Guerrieri et autres (2010), qui appliquent des restrictions aux croyances hors équilibre des vendeurs quant à la probabilité de rencontrer différents types d'acheteurs. L'étude fait en outre ressortir qu'une menace de contrefaçon peut entraîner l'effondrement de l'équilibre monétaire. L'auteur présente une extension du modèle dans laquelle cette menace peut se concrétiser du fait que certains acheteurs n'ont pas connaissance des offres et procèdent par conséquent à la prospection de manière aléatoire. Ce sont ces acheteurs qui peuvent produire de faux billets.

Classification JEL : D82, D83, E42

Classification de la Banque : Billets de banque 


\section{Introduction}

Counterfeiting of bank notes is a societal problem which, to a large extent, falls to central banks to address. To that end, understanding in detail why counterfeiting occurs provides a rationale for central banks to continue deterrence efforts even when counterfeiting seems insignificant 11 This issue essentially concerns the existence of a counterfeiting equilibrium.

This paper investigates whether counterfeiting can occur as a pooling equilibrium in a competitive search environment where sellers make offers, and buyers see the offers and search toward sellers. The emphasis on pooling is that, in reality, people do not accept counterfeit notes willingly $\left.\right|^{2}$ and thus, if counterfeiting occurs, it must be a pooling outcome: counterfeit notes coexist with genuine notes only when people cannot distinguish one from the other. The reason to consider competitive search is threefold $!^{3}$ First, recent papers by Nosal and Wallace (2007), Li and Rocheteau (2011) and $\mathrm{Hu}$ (2011) find that if people can use terms of trade to signal the quality of their money holdings, counterfeiting does not occur at all. The main mechanism for this non-existence result is the signalling structure: an informed buyer makes an offer to an uninformed seller, which permits revelation of true types. However, a competitive search environment, in which uninformed sellers make offers, makes it impossible for buyers to signal themselves. Second, a competitive search environment is a more realistic description of most transactions at the retail level, because a buyer usually observes the price listed for the goods or services, and then decides which store to go to. Third, in the standard monetary search literature, inefficiencies come from three sources: monetary friction, inefficient trading protocol and inefficient matching. Monetary friction is

\footnotetext{
${ }^{1}$ According to the U.S. Treasury Department (2003), "out of the approximately $\$ 600$ billion in U.S. dollars in circulation during FY 2001, the Secret Service reported that about $\$ 49$ million in counterfeit currency was passed on to the public worldwide, or about $\$ 1$ for every $\$ 12,400$ in circulation." The value of counterfeiting in Canada is also relatively small. According to the Bank of Canada's 2012 Annual Report, at the peak of counterfeiting attacks in 2004, the value of counterfeit bank notes passed to the public was $\$ 13$ million, compared to $\$ 42$ billion Canadian bank notes outstanding. This number dropped to $\$ 2.6$ million out of the $\$ 61$ billion of Canadian bank notes in circulation in 2011.

${ }^{2}$ Some studies (e.g., Cavalcanti and Nosal, 2011, Li and Rocheteau, 2011) interpret counterfeiting as a private issuance of money which has positive value and helps to solve the money-shortage problem. According to these studies, sellers knowingly accept counterfeit notes in equilibrium. However, in reality, a shortage of money is unlikely in modern economies and society does not consider counterfeits as private money. Private money is issued by a reputable private institution, such as a commercial bank, and is backed by the issuer's assets. Its design differs from that of government-issued money and so is easily identified. In contrast, counterfeiters aim to produce notes that look like government-issued notes so that unsuspecting merchants will accept them. It is against the law to produce and pass such counterfeits. Therefore, sellers will not accept or recirculate counterfeits if they know the notes are fake.

${ }^{3}$ For a comprehensive review on the models of counterfeiting, please see the survey by Fung and Shao (2011b).
} 
of first-order importance, since it gives rise to the existence of monetary exchange; the others are due to modelling convenience. As the literature points out, formulating the problem in a competitive search environment can get rid of the inefficient trading protocol and matching. So, in the end, whether counterfeiting exists or not, the result is robust and does not depend on an ad-hoc inefficient environment. This is the spirit articulated in Wallace (2010).

In the model, a seller who posts an offer needs to form a belief on how likely it is to meet with different types of buyers. To rule out unreasonable beliefs, this paper adopts the equilibrium concept proposed by Guerrieri et al. (2010) to refine sellers' out-of-equilibrium beliefs. ${ }^{4}$ As a result, an equilibrium with counterfeiting does not exist due to the refinement scheme that allows sellers to screen counterfeiters and discourage buyers from producing counterfeits. The existence of a monetary equilibrium depends on the cost of producing counterfeits, the cost of entry and the inflation rate. If the cost of producing counterfeits is low, or either the cost of entry or inflation is high, there is no monetary equilibrium. This result revives the notion proposed by Nosal and Wallace (2007) that "the threat of counterfeiting can eliminate the monetary equilibrium." Although Nosal and Wallace (2007) were the first to study this threat, as pointed out by Li and Rocheteau (2011), their argument is inconsistent with the belief system that they assumed $5^{5}$ Thus, this paper is the first to show that a threat of counterfeiting can indeed result in the collapse of a monetary equilibrium. This threat distinguishes the counterfeiting of bank notes from other frauds - it can destroy confidence in using bank notes, leading to significant social costs. This result provides a rationale for why central banks should actively respond to the threat despite the extent of counterfeiting being small.

Moreover, this paper shows that the threat of counterfeiting can generate an endogenous resalability constraint. This resalability constraint, which is important in finance to understand asset liquidity and its prices, has been derived in Li and Rocheteau (2009) and Li et al. (2012) under some bargaining protocols. This paper contributes to the existing literature by showing that the constraint is robust and emerges under competitive price posting as well.

After establishing the no-counterfeiting equilibrium, this paper extends the model by introducing some randomness into the search process. The idea is to assume that some buyers

\footnotetext{
${ }^{4} \mathrm{~A}$ recent paper by Fung and Shao (2011a) argues that counterfeit notes and genuine notes can coexist in a pooling equilibrium under this environment. However, they show this result by not putting any restrictions on sellers' out-of-equilibrium beliefs, which leads to indeterminacy of equilibrium.

${ }^{5} \mathrm{Li}$ and Rocheteau claim that Nosal and Wallace's analysis is incorrect. After working out a proper belief system, Li and Rocheteau show that counterfeiting does not pose a threat to the existence of a monetary equilibrium.
} 
are uninformed about the offers posted by sellers, and thus they randomly search, while others still conduct directed search. In doing so, sellers cannot preclude all counterfeiters from visiting them, since some buyers always show up randomly. As a result, equilibrium with counterfeiting can exist when buyers are ex-ante heterogeneous. In this case, those buyers who randomly search may produce counterfeits. The existence of a counterfeiting equilibrium depends on the parameter values: if the costs of producing counterfeits and posting offers are low, and the fraction of uninformed buyers is high, the counterfeiting equilibrium more likely occurs $6^{6}$ The reason is that when more buyers are uninformed, sellers have a strong incentive to create a market with less-desirable terms of trade so that they can extract more rents from the uninformed buyers. At the same time, given the sellers' strategy, when the cost of counterfeiting is small, uninformed buyers find that producing counterfeits is at least as good as holding genuine notes. Hence, counterfeiting occurs in equilibrium. The existence of counterfeiting allows us to discuss related policies. For example, we show that depending on the preferences, higher inflation results in lower counterfeiting.

On the theoretical side, this paper follows the path of recent developments in the competitive search model with asymmetric information 7 Guerrieri et al. (2010) and Chang (2011) study the adverse selection problem where the types are exogenously given and principals post offers to screen different types. In contrast to these papers, here the types are endogenously determined, which leads to a moral hazard problem. Yet, while Delacroix and Shi (2012) also investigate the private information problem which results when the types endogenously arise, they focus on signalling, rather than screening as in our model. Therefore, our paper can be seen as a complement to the existing literature.

\section{The Baseline Model}

The basic economic environment is similar to Rocheteau and Wright (2005). Time is discrete and runs forever. Each period is divided into two subperiods, day and night, during which the market structure differs. During the day, there is a Walrasian market characterized by competitive trading, while at night there is a search market characterized by bilateral trading.

\footnotetext{
${ }^{6}$ It is of interest to note that the counterfeiting rate in Canada rose considerably in the early part of the last decade. According to the existing reports (e.g., Chant, 2004 and RCMP Criminal Intelligence, 2007), one of the possible factors behind this development was the growing availability of low-cost ink-jet color printers and copiers, which substantially reduced the cost of producing counterfeits.

${ }^{7}$ There is also a growing literature on monetary search models with private information, including Williamson and Wright (1994), Berentsen and Rocheteau (2004), Faig and Jerez (2006), Ennis (2008), Shao (2009), Lester et al. (2011), and Dong and Jiang (2011).
} 
There is a continuum of infinitely-lived agents who differ across two dimensions. First, they have private information on some of their own characteristics that will be described in detail later. Second, they belong to one of two groups in the search market, called buyers and sellers. We normalize the measure of buyers to 1 and the measure of sellers is $N>1$. In the Walrasian market all agents produce and consume, but in the search market a buyer can only consume and a seller can only produce. This specification of agents' trading roles in the search market generates a lack-of-double-coincidence-of-wants problem. Therefore, barter is ruled out. All meetings are assumed to be anonymous, which precludes credit. These frictions make a medium of exchange essential in the search market.

Goods are perishable, while (genuine) fiat money is storable, and thus money can potentially be used as a medium of exchange. Money is perfectly divisible and its stock at time $t$ is given by $M_{t}$. The money stock grows at a constant gross rate $\gamma$, so that $M_{t+1}=\gamma M_{t}$. New money is injected $(\gamma>1)$ or withdrawn $(\gamma<1)$ via lump sump transfers to all agents in the Walrasian market. We restrict attention to policies where $\gamma \geq \beta$, where $\beta \in(0,1)$ is the discount factor, since it is easy to check that there is no equilibrium otherwise. To examine what happens when $\gamma=\beta$, which is the Friedman rule, we can take the limit of equilibria as $\gamma \rightarrow \beta$.

Money is perfectly recognizable in the Walrasian market, but imperfectly recognizable in the search market. The recognizability problem of fiat money gives a buyer an incentive to produce counterfeits and extract more surplus in the bilateral trade. Buyers can produce counterfeit notes in any quantity at a fixed cost, $k$, and this decision is private information. Counterfeits are assumed to be $100 \%$ disintegrated or confiscated at the end of each period, as in Nosal and Wallace (2007). As a result, there is no incentive for sellers to produce or pass counterfeits. Sellers can choose to pay cost $L$ to enter the decentralized market.

The instantaneous utility of a seller at date $t$ is

$$
U_{t}^{s}=v\left(x_{t}\right)-y_{t}-q_{t}-L
$$

where $x_{t}$ is the quantity consumed, $y_{t}$ the quantity produced during the day, and $q_{t}$ the quantity produced at night. Lifetime utility for a seller is $\sum_{t=0}^{\infty} \beta^{t} U_{t}^{s}$. We assume that $v^{\prime}(x)>0, v^{\prime \prime}(x)<0$ for all $x$, and there exists $x^{*}>0$ such that $v^{\prime}\left(x^{*}\right)=1$. Similarly, the instantaneous utility of a buyer is

$$
U_{t}^{b}=v\left(x_{t}\right)-y_{t}+u\left(q_{t}\right)-k \mathbb{I}_{\{j=c\}},
$$


where $q_{t}$ is the quantity consumed at night and $\mathbb{I}$ is the indicator function, which is equal to 1 if the buyer chooses to produce counterfeits $(j=c)$ or 0 if the buyer holds only genuine money $(j=g)$. Lifetime utility for a buyer is $\sum_{t=0}^{\infty} \beta^{t} U_{t}^{b}$. Assume that $u(0)=0, u^{\prime}(0)=+\infty$, $u^{\prime}(q)>0$, and $u^{\prime \prime}(q)<0$. There exists $q^{\max }$ and $q^{*}>0$ such that $u\left(q^{\max }\right)=q^{\max }$ and $u^{\prime}\left(q^{*}\right)=1$.

The terms of trade are determined in the competitive search market in the spirit of Rocheteau and Wright (2005) and Guerrieri et al. (2010). Each seller decides whether to incur a cost to enter the search market. Prior to the search process, each seller simultaneously posts an offer that specifies the terms at which buyers and sellers commit to trade. Specifically, an offer is a schedule $\left\{\left(q^{j}, d^{j}\right)\right\}_{j=g, c}$ specifying the quantity traded $q^{j}$ and the total monetary payment $d^{j}$ conditional on the buyer's type $j 8$ We allow sellers to post direct revelation mechanisms specifying that if buyers truthfully reveal their type, sellers implement $\left(q^{j}, d^{j}\right)$. Buyers then observe all the posted offers and direct their search toward those sellers posting the most attractive offer. The set of sellers posting the same offer and the set of buyers directing their search toward them form a submarket. In each submarket, buyers and sellers meet randomly according to the matching function discussed below. When a buyer and a seller meet, the buyer decides to either accept the offer and commit to the terms it specifies, or abandon all trade.

The probability that a buyer and a seller are paired off is independent of the buyer's or seller's type. To focus on the informational frictions and to avoid unnecessary complications, we assume that individuals experience at most one match and that matching is efficient, meaning that the short side of the market is always served in each submarket 9 The probability that a buyer matches a seller is then

$$
\alpha^{b}(\theta(\mathbf{q}, \mathbf{d}))=\min \left(1, \theta^{-1}(\mathbf{q}, \mathbf{d})\right)
$$

where $\theta(\mathbf{q}, \mathbf{d})$ is the ratio of buyers over sellers in each submarket posting an offer $(\mathbf{q}, \mathbf{d}) \equiv$ $\left\{\left(q^{j}, d^{j}\right)\right\}_{j=g, c}$, or the market tightness. Similarly, the probability that a seller matches a buyer is

$$
\alpha^{s}(\theta(\mathbf{q}, \mathbf{d}))=\min (1, \theta(\mathbf{q}, \mathbf{d}))
$$

\footnotetext{
${ }^{8}$ The offer does not include the amount of counterfeits because counterfeits have no value and sellers are not willing to accept them.

${ }^{9}$ This assumption is innocuous if we focus only on the existence of equilibrium, but it matters when characterizing the equilibrium. It turns out that the analysis can be greatly simplified under this assumption, which allows us to fully characterize the set of equilibria.
} 


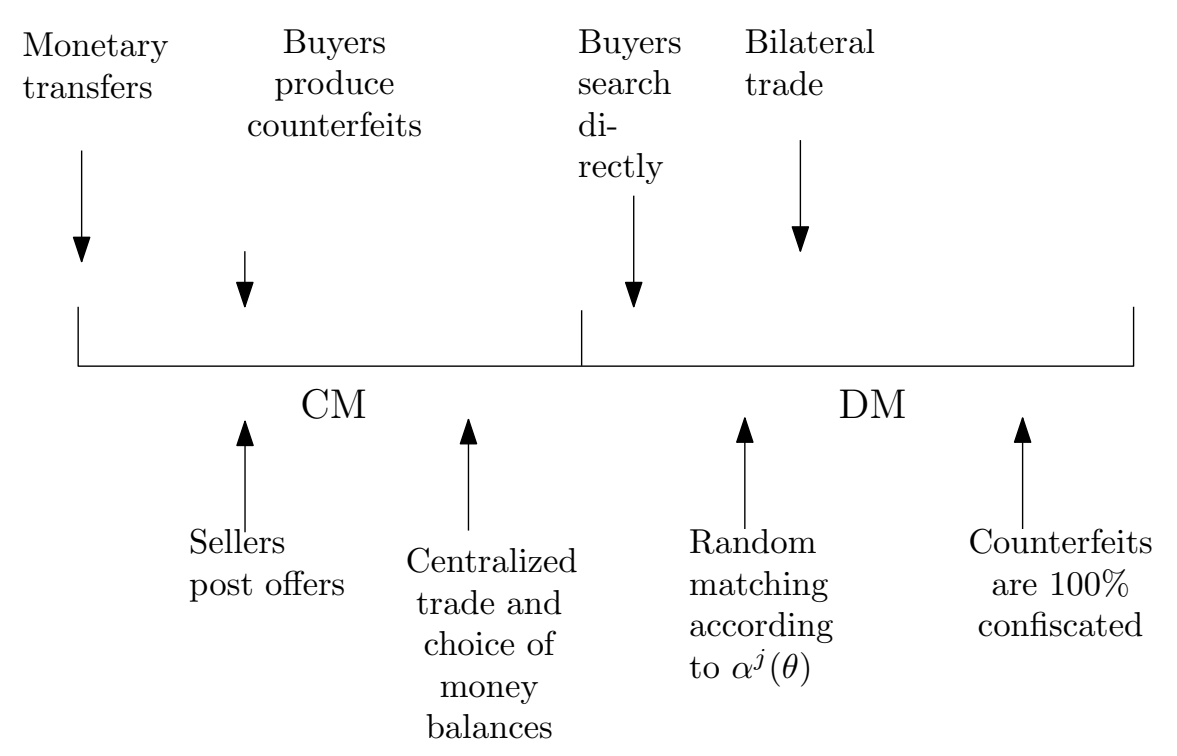

Figure 1: Timing of events in a period

The timing of events in a period is summarized in Figure 1. At the beginning of each period, money is transferred from or back to the government. After that, sellers post their offers for the night market. At the same time, buyers decide whether to produce counterfeits. This decision is private information. Subsequently, the Walrasian market opens, in which agents consume and produce as well as adjust their money balances. When night falls, the Walrasian market closes, and the competitive search market opens. Submarkets are formed as a result of the competitive search process. When a buyer and a seller meet in a submarket, the buyer hands holdings of money to the seller. The pair trade according to the pre-specified terms of trade: the payment is made, the seller produces and the buyer consumes. After matches are terminated, all agents learn the type of their money holdings and all counterfeits disintegrate.

\section{A Threat of Counterfeiting}

Let $P_{t}$ be the fraction of genuine money holders in the economy and $W_{t}^{b}\left(m_{t}\right)$ be the value function of a buyer who enters the Walrasian market at time $t$ holding $m_{t}$ units of money ${ }^{10}$ Since the buyer needs to choose whether to produce a counterfeit, the buyer's value function

\footnotetext{
${ }^{10}$ To simplify the notation, we suppress all aggregate state variables except for money holdings into a subscript $t$ for all the value functions throughout the paper.
} 
at the start of each period is

$$
W_{t}^{b}\left(m_{t}\right)=\max _{p_{t}}\left[p_{t} W_{t}^{g}\left(m_{t}\right)+\left(1-p_{t}\right) W_{t}^{c}\left(m_{t}\right)\right]
$$

where $W^{g}$ and $W^{c}$ represent the value functions of being a holder of genuine money or a counterfeiter, respectively, and $p$ is the choice to hold counterfeits (or to hold genuine money). In equilibrium, $p=P$. The optimal decision on $P$ must satisfy

$$
\begin{cases}P=1 & \text { if } W^{g}>W^{c} \\ P=0 & \text { if } W^{g}<W^{c} \\ P \in[0,1] & \text { if } W^{g}=W^{c}\end{cases}
$$

Denote the buyer's value function of carrying $\hat{m}_{t}$ dollars into the search market of period $t$ by $V_{t}^{g}\left(\hat{m}_{t}\right)$ if the buyer uses only genuine notes, or $V_{t}^{c}\left(\hat{m}_{t}\right)$ otherwise. Similarly, $W_{t}^{s}\left(m_{t}\right)$ and $V_{t}^{s}\left(\hat{m}_{t}\right)$ are the corresponding value functions for the seller. Let the price of the consumption good in the Walrasian market be normalized to 1 and denote the price of a dollar in units of consumption in period $t$ by $\phi_{t}$. The value of the agent $j \in\{s, g, c\}$ in the Walrasian market is

$$
\begin{array}{r}
W_{t}^{j}\left(m_{t}\right)=\max _{x_{t}, y_{t}, \hat{m}_{t}}\left[v\left(x_{t}\right)-y_{t}+V_{t}^{j}\left(\hat{m}_{t}\right)\right], \\
\text { s.t. } x_{t}+\phi_{t} \hat{m}_{t}=y_{t}+\phi_{t}\left(m_{t}+\tau_{t}\right),
\end{array}
$$

where $\tau_{t}$ is the nominal monetary transfers to (or from) the agent ${ }^{11}$

Because utility is quasi-linear, the budget constraint (6) can be substituted into the objective function (5), so that the problem simplifies to

$$
W_{t}^{j}\left(m_{t}\right)=\max _{x_{t}, \hat{m}_{t}}\left[v\left(x_{t}\right)-x_{t}-\phi_{t}\left(\hat{m}_{t}-m_{t}-\tau_{t}\right)+V_{t}^{j}\left(\hat{m}_{t}\right)\right]
$$

Thus, it follows that, for $j \in\{s, g, c\}$,

1. the optimal choice of $x_{t}$ is independent of $m_{t}$ with $v^{\prime}\left(x_{t}\right)=1$, so $x_{t}=x^{*}$;

2. the optimal choice of $\hat{m}_{t}$ is also independent of $m_{t}$, and is determined by maximizing $V_{t}^{j}\left(\hat{m}_{t}\right)-\phi_{t} \hat{m}_{t}$

\footnotetext{
${ }^{11}$ The choices of $x_{t}, y_{t}$ and $\hat{m}_{t}$ are conditional on $j$, but we omit the superscript to ease notation.
} 
3. the value functions $W_{t}^{j}\left(m_{t}\right)$ are linear in $m_{t}$ and can be rewritten as

$$
W_{t}^{j}\left(m_{t}\right)=W_{t}^{j}(0)+\phi_{t} m_{t}
$$

The value functions of buyers and sellers at night depend on the submarket they visit in equilibrium, and on the money holdings they take into this submarket. All agents have rational expectations regarding the number of buyers that will be attracted by each offer that sellers post, and thus about the market tightness in each submarket. Sellers have beliefs regarding the fraction of genuine money holders in each submarket. Let $\delta(\mathbf{q}, \mathbf{d})$ denote the fraction of genuine money holders applying to submarket $(\mathbf{q}, \mathbf{d})$. The value function for the sellers at night is

$$
\begin{aligned}
V_{t}^{s}\left(\hat{m}_{t}\right)= & \alpha^{s}\left(\theta\left(\mathbf{q}_{t}, \mathbf{d}_{t}\right)\right) \delta\left(\mathbf{q}_{t}, \mathbf{d}_{t}\right)\left[-q_{t}^{g}+\beta W_{t+1}^{s}\left(\hat{m}_{t}+d_{t}^{g}\right)\right] \\
& +\alpha^{s}\left(\theta\left(\mathbf{q}_{t}, \mathbf{d}_{t}\right)\right)\left(1-\delta\left(\mathbf{q}_{t}, \mathbf{d}_{t}\right)\right)\left[-q_{t}^{c}+\beta W_{t+1}^{s}\left(\hat{m}_{t}\right)\right] \\
& +\left(1-\alpha^{s}\left(\left(\mathbf{q}_{t}, \mathbf{d}_{t}\right)\right)\right) \beta W_{t+1}^{s}\left(\hat{m}_{t}\right)-L, \\
= & \alpha^{s}\left(\theta\left(\mathbf{q}_{t}, \mathbf{d}_{t}\right)\right) \delta\left(\mathbf{q}_{t}, \mathbf{d}_{t}\right)\left(-q_{t}^{g}+\beta \phi_{t+1} d_{t}^{g}\right) \\
& +\alpha^{s}\left(\theta\left(\mathbf{q}_{t}, \mathbf{d}_{t}\right)\right)\left(1-\delta\left(\mathbf{q}_{t}, \mathbf{d}_{t}\right)\right)\left(-q_{t}^{c}\right) \\
& +\beta\left[\phi_{t+1} \hat{m}_{t}+W_{t+1}^{s}(0)\right]-L .
\end{aligned}
$$

With probability $\alpha^{s}$, a seller will meet with a potential buyer. Conditional on a successful match, the seller will meet a buyer with genuine money with probability $\delta$. With probability $1-\delta$, the seller will meet with a counterfeiter and will suffer a loss in the case when the seller is uninformed. Notice that to derive (8), we use the fact that $W_{t+1}^{s}\left(\hat{m}_{t}\right)$ is linear with slope $\phi_{t+1}$. Combining (7) and (8), the optimal choice of $\hat{m}_{t}$ solves

$$
\max _{\hat{m}_{t} \geq 0}\left(\beta \phi_{t+1}-\phi_{t}\right) \hat{m}_{t}
$$

The solution exists if and only if the inflation rate $\phi_{t} / \phi_{t+1}>\beta$. In this case, $\hat{m}_{t}=0$ and the seller will not carry money to the search market because the seller cannot derive any benefit from holding money. Similarly, the value functions for a buyer at night are, if the buyer is 
holding genuine money,

$$
\begin{aligned}
V_{t}^{g}\left(\hat{m}_{t}\right)= & \max _{\mathbf{q}_{t}, \mathbf{d}_{t}} \alpha^{b}\left(\theta\left(\mathbf{q}_{t}, \mathbf{d}_{t}\right)\right)\left[u\left(q_{t}^{g}\right)+\beta W_{t+1}^{b}\left(\hat{m}_{t}-d_{t}^{g}\right)\right] \mathbb{I}_{\left\{d_{t}^{g} \leq \hat{m}_{t}\right\}} \\
& +\left[\alpha^{b}\left(\theta\left(\mathbf{q}_{t}, \mathbf{d}_{t}\right)\right)\left(1-\mathbb{I}_{\left\{d_{t}^{g} \leq \hat{m}_{t}\right\}}\right)+\left(1-\alpha^{b}\left(\theta\left(\mathbf{q}_{t}, \mathbf{d}_{t}\right)\right)\right)\right] \beta W_{t+1}^{b}\left(\hat{m}_{t}\right) \\
= & \alpha^{b}\left(\theta\left(\mathbf{q}_{t}, \mathbf{d}_{t}\right)\right)\left(u\left(q_{t}^{g}\right)-\beta \phi_{t+1} d_{t}^{g}\right) \mathbb{I}_{\left\{d_{t}^{g} \leq \hat{m}_{t}\right\}}+\beta\left[\phi_{t+1} \hat{m}_{t}+W_{t+1}^{b}(0)\right],
\end{aligned}
$$

and if the buyer is a counterfeiter,

$$
\begin{aligned}
V_{t}^{c}\left(\hat{m}_{t}\right) & =\max _{\mathbf{q}_{t}, \mathbf{d}_{t}}-k+\alpha^{b}\left(\theta\left(\mathbf{q}_{t}, \mathbf{d}_{t}\right)\right) u\left(q_{t}^{c}\right)+\beta W_{t+1}^{b}\left(\hat{m}_{t}\right) \\
& =-k+\alpha^{b}\left(\theta\left(\mathbf{q}_{t}, \mathbf{d}_{t}\right)\right) u\left(q_{t}^{c}\right)+\beta\left[\phi_{t+1} \hat{m}_{t}+W_{t+1}^{b}(0)\right] .
\end{aligned}
$$

Note that the buyer must hold enough genuine money to meet the required contingent payment: $d_{t}^{g} \leq \hat{m}_{t}$. If the buyer does not meet a seller or does not have enough money to pay, and therefore does not trade, the buyer starts the next day with $\hat{m}_{t}$ amounts. Combining (7), (9) and (10), respectively, shows that the genuine buyer holds $\hat{m}=d^{g}$ amounts of money and the counterfeiter carries no genuine money to the search market.

Applying the value functions at night to the value function at the beginning of the day, the daytime values for buyers and sellers can be rewritten as follows:

$$
\begin{aligned}
& W_{t}^{b}\left(m_{t}\right)=v\left(x^{*}\right)-x^{*}+\phi_{t}\left(m_{t}+\tau_{t}\right)+\beta W_{t+1}^{b}(0)+\max _{p_{t}}\left[p_{t} S_{t}^{g}+\left(1-p_{t}\right) S_{t}^{c}\right], \\
& W_{t}^{s}\left(m_{t}\right)=v\left(x^{*}\right)-x^{*}+\phi_{t}\left(m_{t}+\tau_{t}\right)+\beta W_{t+1}^{s}(0) .
\end{aligned}
$$

We restrict our attention to symmetric steady-state equilibrium where the real money balance remains constant. Thus, $\phi_{t+1} M_{t+1}=\phi_{t} M_{t}$ implies that the inflation rate equals the money growth rate: $\phi_{t} / \phi_{t+1}=\gamma$. Given this, the expected trade surpluses of an agent at night are

$$
\begin{aligned}
S^{g} & =\alpha^{b}(\theta(\mathbf{q}, \mathbf{d}))\left(u\left(q^{g}\right)-\beta \frac{\phi}{\gamma} d^{g}\right)-\frac{\gamma-\beta}{\gamma} \phi d^{g} \\
S^{c} & =\alpha^{b}(\theta(\mathbf{q}, \mathbf{d})) u\left(q^{c}\right)-k \\
S^{s} & =\alpha^{s}(\theta(\mathbf{q}, \mathbf{d}))\left[\delta(\mathbf{q}, \mathbf{d})\left(\beta \frac{\phi}{\gamma} d^{g}-q^{g}\right)-(1-\delta(\mathbf{q}, \mathbf{d})) q^{c}\right]-L .
\end{aligned}
$$

Denote the set of equilibrium offers $(\mathbf{q}, \mathbf{d})$ as $\Omega$. One can consider $\Omega$ to consist of a set of active submarkets that can be observed in equilibrium. Let $\bar{S}^{j}$ be the equilibrium expected surplus (or market payoff) at night for $j \in\{s, g, c\}$. Since buyers can direct their search 
toward their preferred offers, their market payoffs must satisfy

$$
\begin{aligned}
& \bar{S}^{g}=\max \left\{0, \max _{(\mathbf{q}, \mathbf{d}) \in \Omega} S^{g}\right\}, \\
& \bar{S}^{c}=\max \left\{0, \max _{(\mathbf{q}, \mathbf{d}) \in \Omega} S^{c}\right\} .
\end{aligned}
$$

The maximization takes into account that buyers can always choose not to trade. Given the market payoffs, condition (4) on $P$ can be rewritten as

$$
\begin{cases}P=1 & \text { if } \bar{S}^{g}>\bar{S}^{c}, \\ P=0 & \text { if } \bar{S}^{g}<\bar{S}^{c}, \\ P \in[0,1] & \text { if } \bar{S}^{g}=\bar{S}^{c} .\end{cases}
$$

To characterize the equilibrium, we need to specify the out-of-equilibrium beliefs as well; i.e., we need to know what happens for $(\mathbf{q}, \mathbf{d}) \notin \Omega$. The restriction on beliefs proposed here is similar to Guerrieri et al. (2010), which is later formalized by Chang (2011). When a seller considers posting a deviating offer $(\mathbf{q}, \mathbf{d}) \notin \Omega$, the seller expects to attract the type of buyer who is most likely to come; that is, the type of buyer who is willing to visit at the lowest matching probability. To demonstrate, let

$$
\theta^{j}(\mathbf{q}, \mathbf{d}) \equiv \sup \left\{\theta^{\prime}>0: S^{j}\left(\theta^{\prime}, \mathbf{q}, \mathbf{d}\right) \geq \bar{S}^{j}\right\}
$$

be the highest buyer-seller ratio for which the type $j \in\{g, c\}$ buyer can be attracted to the deviating offer $(\mathbf{q}, \mathbf{d})$. Then, only those types who find the deviating offer more attractive than other types will enter, in that

$$
\theta(\mathbf{q}, \mathbf{d}) \equiv \sup \left\{\theta^{g}(\mathbf{q}, \mathbf{d}), \theta^{c}(\mathbf{q}, \mathbf{d})\right\}
$$

In this way, the seller's belief is restricted to

$$
\delta(\mathbf{q}, \mathbf{d})= \begin{cases}1 & \text { if } \theta^{g}(\mathbf{q}, \mathbf{d})>\theta^{c}(\mathbf{q}, \mathbf{d}) \\ 0 & \text { if } \theta^{g}(\mathbf{q}, \mathbf{d})<\theta^{c}(\mathbf{q}, \mathbf{d}) \\ P & \text { if } \theta^{g}(\mathbf{q}, \mathbf{d})=\theta^{c}(\mathbf{q}, \mathbf{d})\end{cases}
$$

If the seller can earn positive profit via this adjustment process, the original offer cannot 
be an equilibrium offer. The process will adjust until it is no longer profitable for sellers to deviate.

We define the competitive search equilibrium as follows.

Definition 1. A competitive search equilibrium consists of a set of offers $\Omega$, value functions $W^{b}$ and $W^{s}$, a set of surpluses $\left\{\bar{S}^{g}, \bar{S}^{c}, \bar{S}^{s}\right\}$, beliefs summarized by functions $\theta$ and $\delta$, an aggregate state $P$, a price $\phi$, and the buyer's decision on $p$, all of which satisfy the following conditions.

1. Symmetry: $p=P$.

2. Agent's optimal decision in the CM so that $W^{b}$ and $W^{s}$ satisfy (11) and (12).

3. Sellers' profit maximization and free entry: for any $(\mathbf{q}, \mathbf{d}) \in \Omega$,

$$
\bar{S}^{s}=\max _{\mathbf{q}, \mathbf{d}} S^{s}=0
$$

and for any $(\mathbf{q}, \mathbf{d}) \notin \Omega, \bar{S}^{s}(\theta, \delta)<0$, where $\theta$ and $\delta$ satisfy 17$)$ and 18 .

4. Buyers' optimal search: $\bar{S}^{g}$ and $\bar{S}^{c}$ satisfy (13) and (14).

5. Consistency: beliefs and the buyers' optimal decision on $P$ must be consistent with each other:

$$
\delta(q, d)=P
$$

where $P$ must satisfy 15 .

Because sellers post only incentive-compatible offers, the following lemma shows that the only possible offer is pooling, since counterfeit notes are $100 \%$ confiscated by the government at the end of each period.

Lemma 1. There is no separating offer, i.e. $\left(q^{g}, d^{g}\right)=\left(q^{c}, d^{c}\right)=(q, d)$.

The separating equilibrium cannot be sustained, since the seller does not value counterfeits. This is consistent with what Guerrieri et al. (2010) find: to sustain a separating equilibrium with positive payoffs, the principal (here the seller) must gain enough for the lower type to cover the entry cost. The authors provide an example to show that if lemons are worthless, the entire market always shuts down. However, as we will see below, the notrade equilibrium is not the only equilibrium in which even counterfeit notes are worthless. 
Under some parameter values, the monetary equilibrium can exist. The reason for such a different result is that we are dealing with a hidden-action problem while Guerrieri et al. (2010) are facing an adverse selection problem.

Given Lemma 1 and the fact that all the sellers are identical, it is obvious that there is only one active submarket at night. We then state the following lemma to eliminate search frictions so that we can focus on informational frictions.

Lemma 2. Buyers and sellers trade with probability one in any active submarket: $\theta=$ $\alpha^{b}(\theta)=\alpha^{s}(\theta)=1$.

This lemma is a direct corollary of the assumption regarding the matching process. Note also that there is only one active submarket. If $\theta>1$, for example, then not all buyers will be matched, while all sellers will be matched. Consider a decrease in $\theta$, due to, say, the entry of additional sellers. Then, buyers will have a higher matching probability. It is possible to find another pair of quantities that satisfy all constraints while offering a higher quantity of goods when genuine money is used, and a lower quantity if sellers are uninformed. Obviously, buyers who use genuine money are better off in this case, since they have a higher probability of matching and a higher quantity of goods traded. Therefore, $\theta>1$ cannot be sustained. Similar arguments apply to the case of $\theta<1$.

Since sellers incur a loss when receiving counterfeit notes, they always have incentives to post such offers that can deter people from producing counterfeits. The following proposition shows that sellers can do so in a competitive search equilibrium.

Proposition 1. Counterfeiting cannot happen in any monetary equilibrium, i.e. $P=1$. The equilibrium offer that satisfies Definition 1 must solve the following optimization problem:

$$
\begin{gathered}
\max _{q, d} u(q)-\phi d \\
\text { s.t. } \phi d \leq k, \\
\beta \frac{\phi}{\gamma} d-q=L .
\end{gathered}
$$

Counterfeiting does not occur in equilibrium because it is not incentive-compatible, in that there always exists a deviating offer which allows sellers to earn positive profit. Therefore, in equilibrium, the only offer that can survive the refinement process is the one in which the buyer finds it optimal to hold genuine money rather than produce counterfeits, and the seller believes that it attracts only genuine money holders. Constraint (21) guarantees that 
the offer will be incentive-compatible. This constraint resembles the endogenous resalability constraint derived in Li and Rocheteau (2009), and coincides with that in Li et al. (2012) when the matching probability is one. It specifies that the ability to exchange money for goods depends on the cost of counterfeiting. This in turn implies that liquidity is an endogenous object: it depends on intrinsic properties, which here are captured by the ease of counterfeiting. Note that the endogenous feature of liquidity is robust, since it not only exists in the previous literature under bargaining protocols, but also emerges here under competitive price posting.

Proposition 2. Monetary equilibrium exists if and only if $u^{\prime}(0)>\gamma / \beta$ and $\gamma L / \beta<k$.

Unlike Li and Rocheteau (2009), Proposition 2 states that the existence of monetary equilibrium requires the cost of posting offers and the inflation rate to be small, and the cost of producing counterfeits to be high. This condition is intuitive: if the cost of creating a submarket is too high, then the seller has no incentive to post an offer, because the terms of trade should be bad enough to deter counterfeiting, leading to too little revenue to cover the posting cost. If the inflation rate is high, it is so costly to hold genuine money that the buyer finds it more profitable to produce counterfeits. Similarly, if the cost of producing counterfeits is too low, then the buyer has more incentive to counterfeit. The main reason to generate the link between the existence of monetary equilibrium and the value of $k, \gamma$ and $L$ is the free-entry condition in (22). In $\mathrm{Li}$ and Rocheteau (2009), the seller need not preinvest, so the seller's trade surplus can go to 0, causing the monetary equilibrium to always exist as long as the cost of counterfeiting is positive. However, in the competitive search environment, the seller has to pay a sunk cost to post offers such that no-trade can happen if the gain from trade is not enough to cover this cost. Given the existence of monetary equilibrium relying on the cost of producing counterfeits, Proposition 2 resembles the notion that the threat of counterfeiting can result in the collapse of a monetary equilibrium ${ }^{12}$

\footnotetext{
${ }^{12}$ One could argue that there is no equilibrium in this model, since the seller may deviate from the no-trade equilibrium and post positive $q$ and $d$ in order to trade with a buyer with average quality bank notes; i.e., both genuine buyers and counterfeiters will be attracted to the deviating offer. This is one of the problems in the standard screening model, but it is not true in the competitive search environment. The refinement requires that, when one considers deviations, only those types willing to accept the highest buyer-seller ratio (lowest matching probability) will be attracted to the offer. In this case, if the seller deviates from no-trade equilibrium by increasing $q$ and $d$, then the seller will expect that counterfeiters will be more willing to visit than genuine buyers, because

$$
\theta_{c}=\arg \max \left\{\alpha^{b}(\theta) u(q) \geq 0\right\}>\theta_{g}=\arg \max \left\{\alpha^{b}(\theta)(u(q)-\phi d) \geq 0\right\} .
$$

Therefore, the seller attracts only counterfeiters to visit, not genuine buyers, which makes such a deviation
} 


\section{The Threat to Materialize: Partially Directed Search}

In the baseline model, every buyer can observe the posted offers and direct their search toward the one that yields the maximum surplus. Here, we introduce some randomness in the search process following Lester (2011). The idea is to let some buyers be uninformed about the offer ex ante so that they may randomly visit different submarkets. In this way, on the one hand, sellers cannot preclude counterfeiters from visiting them, because some of them always randomly show up. On the other hand, some sellers might want to post less favorable offers to only serve the uninformed buyers, so that they can extract more surpluses. Given these sellers' strategies, counterfeit notes can pass to them.

The terms of trade at night are still determined by the two-stage process: sellers first post and commit to offers $(q, d)$, and then buyers choose a seller to visit. However, buyers' search is partially directed, in that, in each period, only a fraction $\eta$ of buyers are informed (labelled as $i$ ) and know about both the offers and the locations of all sellers. These buyers will choose to visit the seller who promises the maximum expected payoff. The remaining fraction $1-\eta$ of buyers are uninformed (labelled as $u$ ) and cannot observe the posted offers. Since all sellers appear ex-ante identical to an uninformed buyer, the buyer randomly visits a seller at night.

The sequence of events is depicted in Figure 2. They are similar to the baseline case except that, at the beginning of each period, buyers experience information shock: with probability $\eta$, a buyer can observe the posted offers, while with a complementary probability, the buyer has no information. These shocks are i.i.d. across agents and time. In a stationary environment, the shock on buyers' information revealed at the beginning of the period is equivalent to assuming that buyers are heterogeneous ex ante with respect to information about sellers. In this sense, this case resembles the model of permanent types. For an alternative timing of events, please see the appendix. Here we will show under what conditions counterfeiting can occur in equilibrium.

Following the argument in Lester (2011), it is easy to see that there are at most two submarkets in equilibrium. A profit-maximizing seller will either post $\left(q_{l}, d_{l}\right)$ to serve both informed and uninformed buyers, or post $\left(q_{h}, d_{h}\right)$ to serve only uninformed buyers. Let $\mu$ be the fraction of sellers who are posting $\left(q_{l}, d_{l}\right)$. The decision on $\mu$ characterizes the whole distribution of offers posted in equilibrium. Let $\lambda$ be the fraction of sellers who are actively posting offers in equilibrium. The value of $\lambda$ is determined by the free-entry unprofitable. 


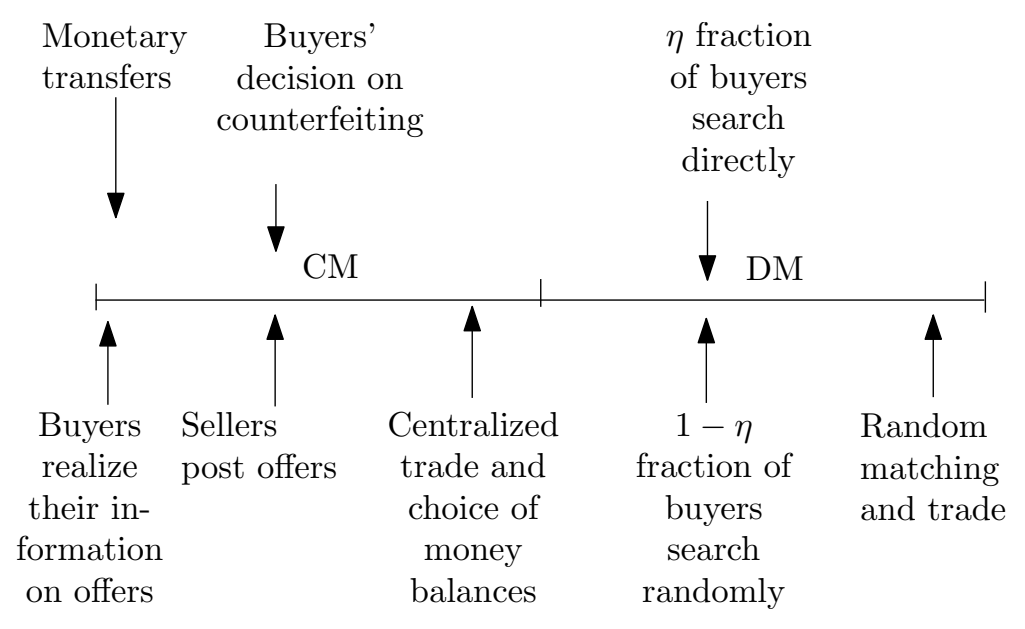

Figure 2: Timing of events in a partially directed search model

condition of sellers. The total measure of sellers posting in each submarket is therefore given by $F\left(q_{l}, d_{l}\right)=\mu \lambda N$ and $F\left(q_{h}, d_{h}\right)=(1-\mu) \lambda N$, respectively. In equilibrium, the market tightness must satisfy the following market clearing condition:

$$
\sum_{j} \theta\left(q_{j}, d_{j}\right) F\left(q_{j}, d_{j}\right)=1
$$

i.e., the number of buyers visiting all submarkets must add up to one.

The day market problems are the same as before. The night market problem can be stated as maximizing the expected surpluses. Denote $\tilde{\eta}\left(q_{j}, d_{j}\right)$ as the belief that the fraction of buyers visiting the submarket $\left(q_{j}, d_{j}\right)$ are informed, while $1-\tilde{\eta}\left(q_{j}, d_{j}\right)$ is the fraction of buyers attracted to $\left(q_{j}, d_{j}\right)$ who are uninformed, for $j=h, l$. In equilibrium, the market clears so that

$$
\sum_{j} \tilde{\eta}\left(q_{j}, d_{j}\right) \theta\left(q_{j}, d_{j}\right) F\left(q_{j}, d_{j}\right) \leq \eta
$$

and

$$
\sum_{j}\left(1-\tilde{\eta}\left(q_{j}, d_{j}\right)\right) \theta\left(q_{j}, d_{j}\right) F\left(q_{j}, d_{j}\right) \leq 1-\eta,
$$

where either equality holds if either type of buyer chooses to enter the submarket. Let $\delta^{i}$ denote the belief of meeting a genuine buyer when this buyer is informed. Similarly, $\delta^{u}$ is the belief of meeting a genuine buyer when this buyer is uninformed. Then, the seller's problem at night is given by

$$
S^{s}=\max _{\mu} \mu S^{s l}+(1-\mu) S^{s h}-L
$$


where

$$
S^{s j}=\alpha^{s}\left(\theta\left(q_{j}, d_{j}\right)\right)\left[\begin{array}{l}
\tilde{\eta}\left(q_{j}, d_{j}\right)\left(\delta^{i}\left(q_{j}, d_{j}\right) \beta \frac{\phi}{\gamma} d_{j}-q_{j}\right) \\
+\left(1-\tilde{\eta}\left(q_{j}, d_{j}\right)\right)\left(\delta^{u}\left(q_{j}, d_{j}\right) \beta \frac{\phi}{\gamma} d_{j}-q_{j}\right)
\end{array}\right],
$$

for $j=h, l$.

There are two types of buyers at the beginning of the period. Each type must decide whether to counterfeit, which is summarized as follows:

$$
S^{j}=\max _{p_{j}} p_{j} S^{g j}+\left(1-p_{j}\right) S^{c j}
$$

for $j=i, u$. Specifically, an informed buyer who chooses to hold genuine money needs to decide which sellers to visit and how much money to acquire in order to buy goods at night. Thus, the expected surplus for this type of buyer is

$$
S^{g i}=\max _{j \in\{h, l\}}\left\{\max _{\hat{m}_{j}} \alpha^{b}\left(\theta\left(q_{j}, d_{j}\right)\right)\left(u\left(q_{j}\right)-\beta \frac{\phi}{\gamma} d_{j}\right) \mathbb{I}_{\left\{d_{j} \leq \hat{m}_{j}\right\}}-\frac{\gamma-\beta}{\gamma} \hat{m}_{j}\right\} .
$$

The optimal money balances derived from (28) must be $\hat{m}_{j}=d_{j}$ for $j=h, l$. The informed buyer who chooses to produce counterfeits needs to pay the cost and search the best offer to apply:

$$
S^{c i}=\max _{j \in\{h, l\}}\left\{\alpha^{b}\left(\theta\left(q_{j}, d_{j}\right)\right) u\left(q_{j}\right)-k\right\} .
$$

For those uninformed buyers, they randomly visit between submarkets. Someone who chooses to hold genuine money must accumulate the maximum balance in order to trade in either submarket. Thus

$$
\begin{aligned}
S^{g u}= & \mu \alpha^{b}\left(\theta\left(q_{l}, d_{l}\right)\right)\left(u\left(q_{l}\right)-\beta \frac{\phi}{\gamma} d_{l}\right) \mathbb{I}_{\left\{d_{l} \leq \hat{m}\right\}} \\
& +(1-\mu) \alpha^{b}\left(\theta\left(q_{h}, d_{h}\right)\right)\left(u\left(q_{h}\right)-\beta \frac{\phi}{\gamma} d_{h}\right) \mathbb{I}_{\left\{d_{h} \leq \hat{m}\right\}}-\frac{\gamma-\beta}{\gamma} \phi \hat{m},
\end{aligned}
$$

and $\hat{m}=\max \left\{d_{h}, d_{l}\right\}$. If someone chooses to produce counterfeits, then

$$
S^{c u}=\mu \alpha^{b}\left(\theta\left(q_{l}, d_{l}\right)\right) u\left(q_{l}\right)+(1-\mu) \alpha^{b}\left(\theta\left(q_{h}, d_{h}\right)\right) u\left(q_{h}\right)-k .
$$

Given $\lambda$, the expected number of uninformed buyers at each seller is $(1-\eta) /(\lambda N)$. Let $\bar{S}^{g i}$ be the expected market value that informed genuine buyers can get at night; i.e., the 
maximal payoff from applying elsewhere. Let $(\bar{q}, \bar{d})$ solve

$$
\alpha^{b}\left(\frac{1-\eta}{\lambda N}\right)\left(u(\bar{q})-\beta \frac{\phi}{\gamma} \bar{d}\right)-\frac{\gamma-\beta}{\gamma} \bar{d}=\bar{S}^{g i} .
$$

Thus, $(\bar{q}, \bar{d})$ is the critical offer above which the seller attracts only uninformed buyers. For any $(q, d)$, such that

$$
\alpha^{b}\left(\frac{1-\eta}{\lambda N}\right)\left(u(q)-\beta \frac{\phi}{\gamma} d\right)-\frac{\gamma-\beta}{\gamma} d \leq \bar{S}^{g i}
$$

only uninformed genuine buyers may visit the submarket. For any $(q, d)$, if

$$
\alpha^{b}\left(\frac{1-\eta}{\lambda N}\right)\left(u(q)-\beta \frac{\phi}{\gamma} d\right)-\frac{\gamma-\beta}{\gamma} d>\bar{S}^{g i}
$$

informed genuine buyers may visit as well. This justifies our original assumption that there exists at most two submarkets, with $\left(q_{h}, d_{h}\right)$ corresponding to (32) and $\left(q_{l}, d_{l}\right)$ satisfying (33). Notice that, since there may be potentially two submarkets in equilibrium, Lemma 2 may not hold and the match probability can be less than 1 , which is different than before. Specifically, if, in equilibrium, there exists two submarkets, then

$$
\begin{aligned}
\theta\left(q_{h}, d_{h}\right) & =\frac{1-\eta}{\lambda N} \\
\theta\left(q_{l}, d_{l}\right) & =\frac{\eta}{\mu \lambda N}+\frac{1-\eta}{\lambda N} .
\end{aligned}
$$

Obviously, if there is only one submarket in equilibrium, then

$$
\theta(q, d)=\frac{1}{\lambda N}
$$

Since uninformed buyers randomly visit submarkets, $\delta^{u}(q, d)=P$ for any $(q, d)$. The refinement on $\delta^{i}$ is similar to previous cases. Specifically, for any $(q, d)$, if $\theta>0$ and $\tilde{\eta}>0$, then

$$
\begin{aligned}
& \delta^{i}=0 \quad \text { when } \quad S^{g i}<\bar{S}^{g i}=\max _{q, d} S^{g i}, \\
& \delta^{i}=1 \quad \text { when } \quad S^{c i}<\bar{S}^{c i}=\max _{q, d} S^{c i}, \\
& \delta^{i}=P \quad \text { otherwise. }
\end{aligned}
$$


To characterize the equilibrium, we first prove the following lemma. This lemma basically says that the informed buyers will only enter the submarket with a lower price $\left(d_{l} / q_{l}\right)$. So, naturally, if $\eta=0$, every buyer is uninformed, and all sellers post a high price $\left(d_{h} / q_{h}\right)$. However, if this is the case, no monetary equilibrium exists, because the seller can extract all the trade surplus from the buyer, which gives the buyer no incentive to carry money. This scenario is the same as when the seller makes a take-it-or-leave-it offer in the random-search model. For $\eta>0$, if there is only one submarket in equilibrium, it must be a low-price market, while, if there are two submarkets in equilibrium, only uninformed buyers will visit the high-price market.

Lemma 3. The equilibrium features $d_{h}=d_{l}$ and $q_{h} \leq q_{l}$.

Interestingly, this lemma also states that the payments specified by the offer are uniform in equilibrium. In principle, informed buyers hold only contingent payment $d_{l}$ and uninformed buyers carry the maximum contingent payment $\left\{d_{l}, d_{h}\right\}$, which may not be the same. If $d_{h}>d_{l}$, then uninformed buyers can choose not to trade in the high-price market, since they get 0 surplus regardless, but by doing so, they can save the cost of carrying money. If $d_{h}<d_{l}$, sellers may want to demand more payment in the high-price market, knowing that uninformed buyers have already held the maximum amount of money available. Thus, $d_{l}=d_{h}$ is necessary.

The next two lemmas are direct corollaries of Proposition 1$]^{13}$ so we omit the proof here. The basic idea is the same as before: sellers can deliberately post offers that are so unattractive that they prevent counterfeiters from applying.

Lemma 4. Informed buyers do not produce counterfeits, i.e., $\delta^{i}=1$.

Lemma 5. If there is only one submarket in equilibrium, counterfeiting cannot occur.

From these two lemmas, we see that counterfeiting can occur only if there are two submarkets, and counterfeiters are only among uninformed buyers. We first show the conditions under which two-submarket equilibrium can exist.

Proposition 3. Denote $\hat{q}=u^{\prime-1}\left(\frac{\gamma}{\beta}\right), L_{1}=u(\hat{q})-\hat{q}, L_{2}=\frac{\beta}{\gamma} k-u^{-1}\left(\frac{\beta}{\gamma} k\right)$ and $L_{3}=\frac{\beta}{\gamma} k-\hat{q}$. Let

$$
\bar{L} \equiv\left\{\begin{array}{ll}
L_{1} & \text { when } \frac{\beta}{\gamma} k>u(\hat{q}) \\
L_{2} & \text { when } \frac{\beta}{\gamma} k \leq u(\hat{q})
\end{array} .\right.
$$

The following must be true.

\footnotetext{
${ }^{13}$ They are also corollaries of Proposition 6 in the appendix.
} 


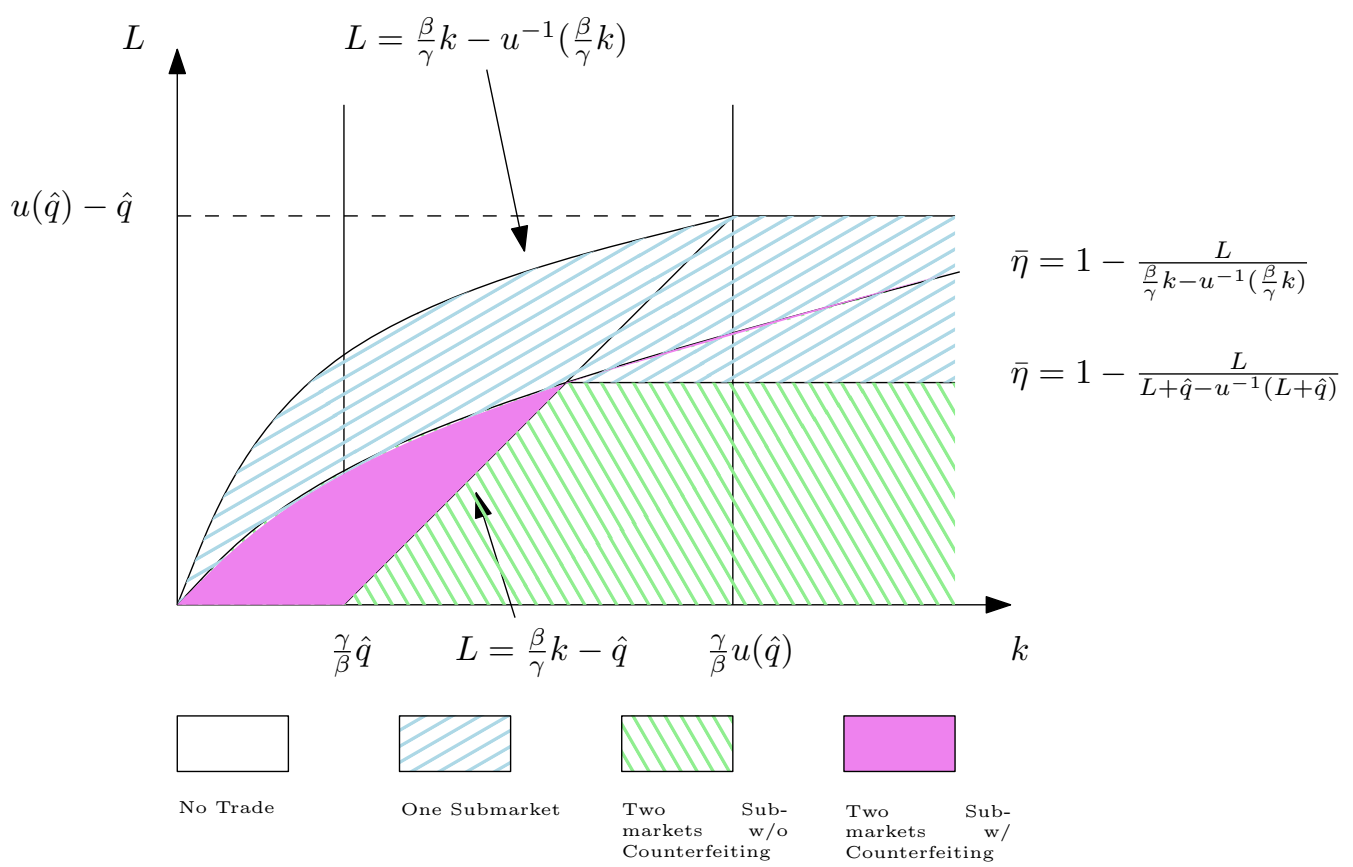

Figure 3: Characterization of equilibrium under different costs, $L$ and $k$

1. Active equilibrium does NOT exist if $L \geq \bar{L}$.

2. If $L<\bar{L}$, then there exists a $\bar{\eta}$ such that, for any $\eta \geq \bar{\eta}$, only one submarket exists in equilibrium, while for any $\eta<\bar{\eta}$, equilibrium with two submarkets exists. The cut-off value $\bar{\eta}$ is given by:

(a) when $\frac{\beta}{\gamma} k<\hat{q}$, if $L<L_{2}$, then $\bar{\eta}=1-\frac{L}{\frac{\beta}{\gamma} k-u^{-1}\left(\frac{\beta}{\gamma} k\right)}$;

(b) when $\hat{q} \leq \frac{\beta}{\gamma} k \leq u(\hat{q})$, if $L_{3}<L<L_{2}$, then $\bar{\eta}=1-\frac{L}{\frac{\beta}{\gamma} k-u^{-1}\left(\frac{\beta}{\gamma} k\right)}$, while if $L \leq L_{3}$, $\bar{\eta}=1-\frac{L}{L+\hat{q}-u^{-1}(L+\hat{q})} ;$

(c) when $\frac{\beta}{\gamma} k>u(\hat{q})$, if $L<L_{1}$, then $\bar{\eta}=1-\frac{L}{L+\hat{q}-u^{-1}(L+\hat{q})}$.

Proposition 3 tells us that, for a given cost of counterfeiting, there exists a threshold value for the cost of posting offers, $\bar{L}$, where, if this cost is high, then sellers will not trade in the market. If $L$ is below $\bar{L}$, then sellers would like to post two prices only when the fraction of uninformed buyers is big; otherwise, they will only post one price. Figure 3 summarizes the findings. Given these findings, the next proposition shows when counterfeiting equilibrium exists. 
Proposition 4. Monetary equilibrium with counterfeiting exists if and only if either of the following cases holds.

1. $\frac{\beta}{\gamma} k<\hat{q}, L<L_{2}$ and $\eta<\bar{\eta}$.

2. $\hat{q} \leq \frac{\beta}{\gamma} k \leq u(\hat{q}), L_{3}<L<L_{2}$, and $\eta<\bar{\eta}$.

However, the counterfeiting equilibrium is not unique and there is a continuum of such equilibria.

In general, counterfeiting equilibrium exists if the cost of producing counterfeits and the cost of entry is small and the fraction of uninformed buyers is big. When the fraction of uninformed buyers is big enough, sellers would like to create two submarkets with one highprice market to extract more rents from uninformed buyers. On the one hand, uninformed buyers can attain the maximum surpluses by holding genuine money once they randomly visit the low-price market. On the other hand, by producing counterfeits, uninformed buyers can extract some surpluses from sellers even though they sometimes enter the high-price market. Therefore, the uninformed buyers can gain surplus by either holding genuine notes or producing counterfeits. As long as these gains are equal, counterfeiting equilibrium can exist. Intuitively, the cost of counterfeiting should be small; otherwise, uninformed buyers will prefer to hold genuine notes. Given that sellers can post offers that affect only the search decisions of informed buyers (but not uninformed), informed buyers will never counterfeit in equilibrium. Figure 3 provides a detailed description of equilibrium.

It is obvious from the above discussion that policies aimed at raising the cost of counterfeiting, such as increased bank note security or enhanced law enforcement, can effectively reduce counterfeiting. However, it is less clear on how inflation changes the equilibrium of counterfeiting. This is due to the fact that inflation can reduce the real value of money. On the one hand, it is a tax on the holder of genuine money, which reduces the buyer's incentive to hold money. On the other hand, a decrease in the real value of money causes the gain of counterfeiters from trade to drop, leading to less willingness to produce counterfeits. These two opposite forces drive the ambiguous total effect of inflation. Figure 4 shows two different scenarios of an increase in inflation on the set of counterfeiting equilibria. The right panel shows that the fall in the counterfeiter's surplus dominates the fall in the genuine money holder's surplus so that the set of counterfeiting equilibria shrinks. The left panel shows the opposite, such that some regions, where counterfeiting did not occur before, now have counterfeiting equilibrium. In general, the total effect of inflation depends on the curvature 

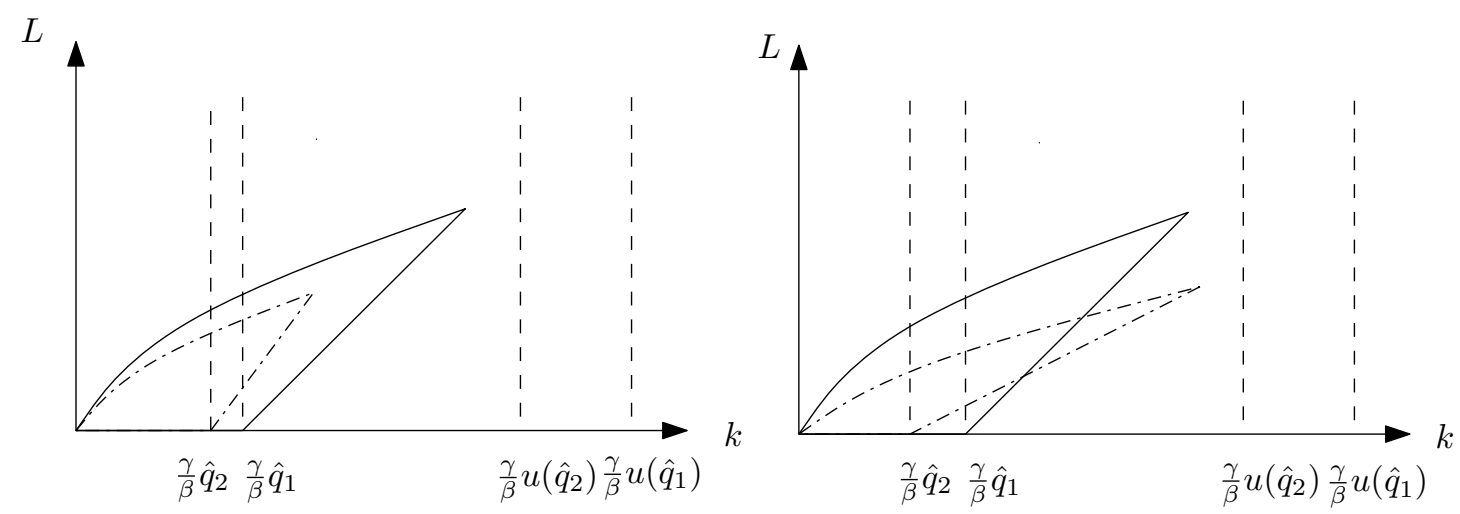

Figure 4: Effects of inflation on counterfeiting.

Note: The solid lines represent the original set of counterfeiting equilibria. The dash-dot lines represent the new set due to an increase in inflation.

of preference. The following proposition illustrates that, if the utility function is constant relative risk aversion and close to linear, then inflation can help to deter counterfeiting.

Proposition 5. Suppose that $u(q)=q^{1-\sigma} /(1-\sigma)$. An increase in $\gamma$ will decrease the size of counterfeiting equilibrium set if $\sigma \rightarrow 0$.

\section{Conclusion}

This paper examines the existence of counterfeiting equilibrium in a competitive search environment. The main finding is that if an individual's beliefs are restricted in a reasonable way, counterfeiting does not occur. However, the possibility of counterfeiting can be a threat to the monetary system. In a competitive search environment, sellers have enough instruments to induce buyers not to produce counterfeits, knowing that counterfeiters care about only the quantity of goods and not payments, while genuine buyers care about both. Ex ante heterogeneity in the search process can partly shut down the seller's screening ability, so that counterfeiting can exist.

Given that counterfeiting occurs in a special case where people conduct a partially directed search, how can we link this result to real world experience? I attempt to interpret those people who are uninformed as foreigners and those who are informed as locals. By interpreting this way, the result is somewhat close to that seen in past and current counterfeiting activities ${ }^{14}$ During the free banking era, many large and long-lived counterfeiting

\footnotetext{
${ }^{14} \mathrm{~A}$ useful history of counterfeiting is provided in Powell and Moxley (2012) for the Canadian experience,
} 
operations of U.S. bank notes were found in Canada. Most of them were located in the Eastern Townships of Lower Canada, close to the U.S. border. These foreign counterfeiters made bogus U.S. bank notes that were shipped to major cities in the U.S. East Coast for distribution. In more recent experience, evidence indicates that many counterfeit U.S. dollars passed in the United States originate from overseas. For example, according to the U.S. Treasury Department (2003), 41 per cent of the $\$ 47.5$ million in counterfeit currency passed in the United States in 2001 was determined to come from Colombia. In Canada, a similar trend can be found: the bulk of U.S.-dollar counterfeits are imported from outside of Canada (and not just from the United States) and passed by foreigners in local casinos and high-end retail stores (RCMP Criminal Intelligence, 2007) ${ }^{15}$

and in Mihm (2007) for the United States.

${ }^{15}$ Interestingly, the phenomenon that foreigners produce and distribute forged notes in the local community exists in other types of fraud as well. The most notable example is wildcat banks, which were established with little or no capital for the sole purpose of defrauding the public by circulating near-worthless notes. Many wildcat banks were opened in remote areas; however, their notes, engraved to resemble those of honest banks, were pushed into local society. 


\section{A Appendix}

\section{A.1 Omitted Proofs}

Proof of Lemma 1. Sellers do not produce in exchange for a counterfeit because, by assumption, counterfeits have no future values. If there exists a separating contract, it implies that $q^{g} \neq q^{c}$. If $q^{g}>q^{c}$, then a counterfeiter will always prefer the contract for genuine money holders, since a counterfeiter can produce any amount of counterfeit money. If $q^{g}<q^{c}$, then a seller can offer $q^{\prime}$ (and keep the same or slightly higher amount of payments), where $q^{g}<q^{\prime}<q^{c}$. In this way, the seller can attract only the buyers holding genuine money, since they are more willing to accept the offer than counterfeiters at the lower matching probability. Therefore, there will not be a separating offer.

Proof of Lemma 2. Suppose $\theta>1$ in equilibrium for any $(q, d)$. This implies that $\alpha^{b}(\theta)<$ 1 and $\alpha^{s}(\theta)=1$. Consider an arbitrary $\theta^{\prime} \in(1, \theta)$ such that $\alpha^{b}\left(\theta^{\prime}\right)>\alpha^{b}(\theta)$. Fixing the same payment $d$, we can find a quantity $q^{\prime}$ together with $\theta^{\prime}$ so that buyers are indifferent entering market $(\theta, q, d)$ and market $\left(\theta^{\prime}, q^{\prime}, d\right)$. Specifically, this can be done by choosing $q^{\prime}<q$ to satisfy

$$
\alpha^{b}(\theta) u(q)=\alpha^{b}\left(\theta^{\prime}\right) u\left(q^{\prime}\right)
$$

Thus $\bar{S}^{g}=\bar{S}^{g \prime}$ and $\bar{S}^{c}=\bar{S}^{c \prime}$. The optimal choice of $P$ remains the same, as the surpluses do not change. As a result, the seller's belief on $\delta$ remains the same. Therefore, the seller can earn a positive profit, since $q^{\prime}<q$ and all other terms remain the same in the seller's surplus. This contradicts the free-entry condition.

Next, suppose $\theta<1$ in equilibrium, which implies that $\alpha^{b}(\theta)=1$ and $\alpha^{s}(\theta)<1$. For a given arbitrary $\theta^{\prime} \in(\theta, 1)$, we can find $d^{\prime}=d-\varepsilon$ and $q$ are fixed, so that genuine money holders are attracted to the deviating offer, while counterfeiters are not. In this case, $\delta\left(q, d^{\prime}\right)=1$. The seller will be better off as long as the surplus is

$$
\bar{S}^{s \prime}=\alpha^{s}\left(\theta^{\prime}\right)\left(\beta \frac{\phi}{\gamma} d^{\prime}-q\right)>\alpha^{s}(\theta)\left(\delta \beta \frac{\phi}{\gamma} d-q\right)=\bar{S}^{s} .
$$

The above inequality holds if

$$
\varepsilon<\frac{\left(\alpha^{s}\left(\theta^{\prime}\right)-\alpha^{s}(\theta)\right)\left(d-\frac{\gamma}{\beta \phi} q\right)}{\alpha^{s}\left(\theta^{\prime}\right)} .
$$


A violation of condition 2 in Definition 1 .

Proof of Proposition 1. Suppose there exists a monetary equilibrium with counterfeiting, i.e., $q>0, d>0, P \in(0,1)$ and $\bar{S}^{g}=\bar{S}^{c}$. Consider a deviating offer $\left(q^{\prime}, d^{\prime}\right)$ with $q^{\prime}=q-\varepsilon$ for some $\varepsilon>0$. Obviously, counterfeiters will not be attracted to this offer, since they care only about the amount of goods they can consume and not the amount of money that the seller charges. However, the seller can lower the payment so that genuine buyers are indifferent between $(q, d)$ and $\left(q^{\prime}, d^{\prime}\right)$. This requires

$$
\left(u(q)-\beta \frac{\phi}{\gamma} d\right)-\frac{\gamma-\beta}{\gamma} \phi d=\left(u\left(q^{\prime}\right)-\beta \frac{\phi}{\gamma} d^{\prime}\right)-\frac{\gamma-\beta}{\gamma} \phi d^{\prime}
$$

so that

$$
d^{\prime}=d-\frac{u^{\prime}(\hat{q}) \varepsilon}{\phi},
$$

where $\hat{q} \in\left[q^{\prime}, q\right]$. Given $\left(q^{\prime}, d^{\prime}\right), \delta\left(q^{\prime}, d^{\prime}\right)=1$, since only genuine buyers might be attracted to this offer. The seller's profit is then $\beta \frac{\phi}{\gamma} d^{\prime}-q^{\prime}-L$. We want to check whether the seller can earn a positive profit for some $\varepsilon>0$. That is,

$$
\beta \frac{\phi}{\gamma} d^{\prime}-q^{\prime}-P \beta \frac{\phi}{\gamma} d+q>0
$$

When $u^{\prime}(\hat{q}) \leq \gamma / \beta$, the above inequality is automatically satisfied for any $\varepsilon>0$. If $u^{\prime}(\hat{q})>\gamma / \beta$, then the inequality holds if $\varepsilon<(1-P) \beta \phi d /\left(\beta u^{\prime}(\hat{q})-\gamma\right)$. Therefore, the deviating offer $\left(q^{\prime}, d^{\prime}\right)$ will make the seller better off, which violates condition 2 in Definition 1. Given $\delta=1$, consistency requires that $S^{g} \geq S^{c}$, which boils down to constraint (21). It is straightforward to verify that the optimization problem (20) - 222) satisfies all equilibrium conditions from Definition (1).

Proof of Proposition 2. First, note that constraint (22) must bind for any monetary equilibrium; otherwise, the buyer can increase consumption $q$ while constraints still hold. From (22), we can see that if $q>0$, it must be $\phi>0$ as well. Because $\bar{S}^{g}=u(q)-\phi d \geq 0$, money is valued only if $q>0$. Hence, monetary equilibrium exists if and only if $q>0$. Substituting (22) into (21) yields

$$
\frac{\gamma}{\beta}(q+L) \leq k .
$$

It is necessary that $\gamma L / \beta<k$ to have (38) hold for any $q>0$. Then, the first-order condition 
for the optimization problem becomes

$$
u^{\prime}(q)-(1-\lambda) \frac{\gamma}{\beta} \leq 0, \text { with equality if } q>0
$$

where $\lambda$ is the Lagrangian multiplier of (38). $\lambda$ equals 0 when $q=0$ given $\gamma L / \beta<k$. Therefore, $q>0$ if and only if $u^{\prime}(0)>\gamma / \beta$.

Proof of Lemma 3. Fixing arbitrary $\mu, \lambda$ and $P$, we look at the offers posting in each submarket. First, it is not possible that $d_{l}>d_{h}$ and $q_{l}<q_{h}$, because otherwise the informed buyers will choose to visit submarket $h$ instead of $l$. In submarket $h$, the seller maximizes profit by posting $\left(q_{h}, d_{h}\right)$ to attract only uninformed buyers. Then $\tilde{\eta}\left(q_{h}, d_{h}\right)=0$. Therefore, the offer should solve the following problem:

$$
\begin{array}{cl} 
& \bar{S}^{s h}=\max _{q, d} \alpha^{s}\left(\frac{1-\eta}{\lambda N}\right)\left(P \beta \frac{\phi}{\gamma} d-q\right)-L \\
\text { s.t. } & \alpha^{b}\left(\frac{1-\eta}{\lambda N}\right)\left(u(q)-\beta \frac{\phi}{\gamma} d\right) \geq 0 .
\end{array}
$$

Notice that the participation constraint 40 requires only that the trade surplus for buyers who entered the submarket be non-negative, and not that the total surplus before acquiring money be non-negative. This is due to the fact that buyers are uninformed, so that sellers have monopoly power to extract all rents. In this sense, this submarket acts as sellers making a take-it-or-leave-it offer. In submarket $l$, sellers compete to attract informed buyers. The terms of trade are determined by

$$
\begin{gathered}
\max _{q, d} \eta \alpha^{b}(\theta(q, d))\left(u(q)-\beta \frac{\phi}{\gamma} d\right)-\frac{\gamma-\beta}{\gamma} \phi d \\
\text { s.t. } \mu \alpha^{s}(\theta(q, d))\left[\begin{array}{c}
\tilde{\eta}(q, d)\left(\delta^{i}(q, d) \beta \frac{\phi}{\gamma} d-q\right) \\
+(1-\tilde{\eta}(q, d))\left(P \beta \frac{\phi}{\gamma} d-q\right)
\end{array}\right]+(1-\mu) \bar{S}^{s h}-L \leq 0, \\
\delta^{i}(q, d) \text { satisfies (37), } \\
\tilde{\eta} \text { satisfies 24) and (25). }
\end{gathered}
$$

If $d_{h}<d_{l}$, then keep $\left(q_{l}, d_{l}\right)$ the same and consider Problem (39) to increase $d_{h}$ by an arbitrary small $\varepsilon>0$, such that $d_{h}^{\prime}=d_{h}+\varepsilon \leq d_{l}$. Then, increase $q_{h}$ to $q_{h}^{\prime}$ so that the participation constraint (40) still holds, which requires

$$
u\left(q_{h}^{\prime}\right)=u\left(q_{h}\right)+\beta \frac{\phi}{\gamma} \varepsilon \leq u\left(q_{l}\right)
$$


By concavity of $u$, we can see that $\left(q_{h}^{\prime}, d_{h}^{\prime}\right)$ yields higher profits for sellers while satisfying the buyer's participation constraint. This contradicts that $\left(q_{h}, d_{h}\right)$ is an equilibrium.

If $d_{l}<d_{h}$, from the seller's maximization problem in (39), the constraint (40) must be binding. Thus, the uninformed genuine buyer will receive zero trade surplus. Then, from (30), the buyer will choose $\hat{m}=d_{l}$ to save the cost of holding money. If this is the case, then the high-price market will never be active, which contradicts the assumption.

Proof of Proposition 3. If sellers decide to post in the low-price market, the offer $\left(q_{l}, d_{l}\right)$ must solve the following optimization problem:

$$
\begin{gathered}
\max _{q_{l}, d_{l}, \lambda} \alpha^{b}\left(\theta_{l}\right)\left(u\left(q_{l}\right)-\beta \frac{\phi}{\gamma} d_{l}\right)-\frac{\gamma-\beta}{\gamma} \phi d_{l} \\
\text { s.t. } \mu \alpha^{s}\left(\theta_{l}\right)\left[\begin{array}{l}
\tilde{\eta}\left(q_{l}, d_{l}\right)\left(\beta \frac{\phi}{\gamma} d_{l}-q_{l}\right) \\
+\left(1-\tilde{\eta}\left(q_{l}, d_{l}\right)\right)\left(P \beta \frac{\phi}{\gamma} d_{l}-q_{l}\right)
\end{array}\right]+(1-\mu) \bar{S}^{s h} \leq L, \\
\alpha^{b}\left(\theta_{l}\right) u\left(q_{l}\right)-k \leq \alpha^{b}\left(\theta_{l}\right)\left(u\left(q_{l}\right)-\beta \frac{\phi}{\gamma} d_{l}\right)-\frac{\gamma-\beta}{\gamma} \phi d_{l}, \\
\theta_{l}=\left(\frac{\eta}{\mu}+1-\eta\right) \frac{1}{\lambda N} .
\end{gathered}
$$

The second inequality is the no-counterfeiting constraint derived from Lemma 4. If sellers post in the high-price market, the offer $\left(q_{h}, d_{h}\right)$ solves the following problem:

$$
\begin{gathered}
\\
\quad \bar{S}^{s h}=\max _{q_{h}, d_{h}} \alpha^{s}\left(\theta_{h}\right)\left(P \beta \frac{\phi}{\gamma} d_{h}-q_{h}\right)-L \\
\text { s.t. } \quad \alpha^{b}\left(\theta_{h}\right)\left(u\left(q_{h}\right)-\beta \frac{\phi}{\gamma} d_{h}\right) \geq 0, \\
\theta_{h}=\frac{1-\eta}{\lambda N} .
\end{gathered}
$$

Immediately, it yields $u\left(q_{h}\right)=\beta \frac{\phi}{\gamma} d_{h}$.

If all sellers post the same price, then $\mu=1$, there is only one submarket, and the submarket must be low-price. Following Lemma 2, it is straightforward to see that $\theta_{l}=1$, 
which implies $\lambda=1 / N{ }^{16}$ The optimization problem then becomes

$$
\begin{aligned}
& \quad \max _{q_{l}, d_{l}} u\left(q_{l}\right)-\phi d_{l} \\
& \text { s.t. } \beta \frac{\phi}{\gamma} d_{l}-q_{l} \leq L . \\
& \phi d_{l} \leq k .
\end{aligned}
$$

Obviously, the seller's free-entry condition (51) must hold with equality. Then, the solution to $(50)-(52)$ depends on whether constraint (52) binds or not. If (52) does not bind, then

$$
\left\{\begin{array}{l}
u^{\prime}\left(q_{l}\right)=\frac{\gamma}{\beta} \\
\phi d_{l}=\frac{\gamma}{\beta}\left(L+q_{l}\right)
\end{array} .\right.
$$

This happens if and only if $u^{\prime}(\beta k / \gamma-L) \leq \gamma / \beta$, i.e., $\beta k / \gamma-L \geq u^{\prime-1}(\gamma / \beta)=\hat{q}$. When $u^{\prime}(\beta k / \gamma-L)>\gamma / \beta$, i.e., $\beta k / \gamma-L<\hat{q}$, (52) binds, then the solution is

$$
\left\{\begin{array}{l}
q_{l}=\frac{\beta}{\gamma} k-L \\
\phi d_{l}=k
\end{array} .\right.
$$

The sellers find that it is optimal to post at the same market if and only if

$$
\beta \frac{\phi}{\gamma} d_{l}-q_{l} \geq \alpha^{s}\left(\theta_{h}\right)\left(\beta \frac{\phi}{\gamma} d_{h}-q_{h}\right) .
$$

Otherwise, sellers will post at different markets. The left-hand side of (53) is equal to $L$ by free entry. Given $\lambda N=1, \theta_{h}=1-\eta$ and $\alpha^{s}\left(\theta_{h}\right)=1-\eta$. Also, $q_{h}=u^{-1}\left(\beta \frac{\phi}{\gamma} d_{h}\right)=$ $u^{-1}\left(\beta \frac{\phi}{\gamma} d_{l}\right)$ where the last equality follows from Lemma 3 .

Depending on the value of $k$, there are three cases to be considered.

1. $\beta k / \gamma<\hat{q}$. Then $\beta k / \gamma-L<\hat{q}$ for any $L \geq 0$. Constraint (52) always binds. Inequality

\footnotetext{
${ }^{16}$ Suppose $\theta_{l}>1$. Then, $\alpha^{b}\left(\theta_{l}\right)<1$ and $\alpha^{s}\left(\theta_{l}\right)=1$. We can increase $\theta_{l}$ to $\theta_{l}^{\prime}$ and decrease $d_{l}$ to $d_{l}^{\prime}$ while keeping $q_{l}$ the same such that $\alpha^{b}\left(\theta_{l}\right) d_{l}=\alpha^{b}\left(\theta_{l}^{\prime}\right) d_{l}^{\prime}$. By doing so, constraints 46) and (47) are still satisfied, but the buyer's surplus in problem (45) is higher, which is a contradiction. Now suppose $\theta_{l}<1$. Then, $\alpha^{b}\left(\theta_{l}\right)=1$ and $\alpha^{s}\left(\theta_{l}\right)<1$. We can increase both $\theta_{l}$ and $q_{l}$ and keep $d_{l}$ the same, so that 46 still holds. This change will not affect 47). However, this change yields a higher surplus for the buyer, which leads to a contradiction. Hence, in equilibrium, $\theta_{l}=1$.
} 
(53) holds if and only if

$$
\eta \geq 1-\frac{L}{\frac{\beta}{\gamma} k-u^{-1}\left(\frac{\beta}{\gamma} k\right)} .
$$

(54) exists if and only if

$$
L<\frac{\beta}{\gamma} k-u^{-1}\left(\frac{\beta}{\gamma} k\right)=L_{2} .
$$

However, if $L \geq \beta k / \gamma-u^{-1}(\beta k / \gamma)$, then the quantity

$$
q_{l}=\frac{\beta}{\gamma} k-L \leq u^{-1}\left(\frac{\beta}{\gamma} k\right)=q_{h},
$$

which is not possible in any active equilibrium.

2. $\hat{q} \leq \beta k / \gamma \leq u(\hat{q})$. Then if

$$
L>\frac{\beta}{\gamma} k-\hat{q}=L_{3},
$$

(52) always binds. Again, inequality (53) requires that (54) hold, which in turn requires that the necessary and sufficient condition (55) hold. Therefore, $L_{3}<L<L_{2}$ is required to have one-submarket equilibrium exist. When $L \geq L_{2}$, no active equilibrium can exist, due to the same argument as before. If $L \leq L_{3}$, then (52) never binds. (53) holds if and only if

$$
\eta \geq 1-\frac{L}{L+\hat{q}-u^{-1}(L+\hat{q})} .
$$

(57) exists if and only if

$$
\frac{L}{L+\hat{q}-u^{-1}(L+\hat{q})}<1
$$

which is equivalent to $L<u(\hat{q})-\hat{q}=L_{1}$. Since $\beta k / \gamma \leq u(\hat{q})$, it implies that $L_{3} \leq L_{1}$. $L \leq L_{3}$ guarantees that (57) holds.

3. $\beta k / \gamma>u(\hat{q})$. We claim that constraint (52) never binds for any $L \geq 0$. Suppose $\phi d_{l}=k$. Then, the genuine buyer's expected surplus is $u(\hat{q})-\beta k / \gamma<0$. Because the buyers are free to participate in the market, they will not enter such a market. This market will not be created in equilibrium. Hence, $\phi d_{l}<k$. Then, (53) requires that (57) holds, which requires $L<L_{1}$. However, if $L \geq L_{1}$, then the genuine buyer's surplus in (50) implies that

$$
S^{g i}=u(\hat{q})-\frac{\gamma}{\beta} \hat{q}-\frac{\gamma}{\beta} L \leq u(\hat{q})-\frac{\gamma}{\beta} \hat{q}-\frac{\gamma}{\beta}(u(\hat{q})-\hat{q})<0 .
$$


The genuine buyer will not trade. Thus, no active equilibrium exists.

Proof of Proposition 4. We have established in Lemmas 4 and 5 that the counterfeiting equilibrium exists only if there are two submarkets and uninformed buyers may choose to produce counterfeits. In this case, the sellers cannot use offers to separate counterfeiters and genuine buyers, since all counterfeiters randomly visit them. In Proposition 3, we have shown that it is necessary and sufficient to have $\eta<\bar{\eta}$ for the existence of two-submarket equilibrium. Then, the uninformed buyers choose to produce counterfeits if and only if $S^{g u}=S^{c u}$. Given $u\left(q_{h}\right)=\beta \frac{\phi}{\gamma} d_{h}$ and $d_{h}=d_{l}$, this requires that

$$
k=(1-\mu) \alpha^{b}\left(\theta_{h}\right) \frac{\beta}{\gamma} \phi d_{h}+\left(1-\frac{\beta}{\gamma}+\mu \alpha^{b}\left(\theta_{l}\right) \frac{\beta}{\gamma}\right) \phi d_{l} .
$$

Using the same argument as in footnote 16 , we can show that $\theta_{l}=1$, which implies

$$
\lambda=\left(\frac{\eta}{\mu}+1-\eta\right) \frac{1}{N}
$$

Given this, $\theta_{h}=(1-\eta) /\left(\frac{\eta}{\mu}+1-\eta\right)<1$. Hence, $\alpha^{b}\left(\theta_{h}\right)=\alpha^{b}\left(\theta_{l}\right)=1$. Then, condition (59) becomes $k=\phi d_{l}$. From the maximization problem in the low-price market 45), the constraint $\phi d_{l} \leq k$ does not bind if and only if $\beta k / \gamma-L \geq \hat{q}$ when $P=1$. From the proof of Proposition 3, we see that $\phi d_{l}=k$ if and only if (i) $\frac{\beta}{\gamma} k<\hat{q}, L<L_{2}$ and $\eta<\bar{\eta}$, or (ii) $\hat{q} \leq \frac{\beta}{\gamma} k \leq u(\hat{q}), L_{3}<L<L_{2}$, and $\eta<\bar{\eta}$.

The conditions that characterize the counterfeiting equilibrium include (i) $\bar{S}^{s l}=\bar{S}^{s h}$, (ii) $\bar{S}^{g i} \geq \bar{S}^{c i}$, and (iii) $\bar{S}^{g u}=\bar{S}^{c u}$. However, conditions (ii) and (iii) collapse into one equation. Therefore, in general, equilibrium is not unique and there exists a continuum of equilibria.

Proof of Proposition 5. From Proposition 4, the counterfeiting equilibrium set is characterized by two conditions. We want to show that the bounds outlined in these two conditions are smaller if the inflation rate is higher. First, notice that $u^{\prime}(\hat{q})=\gamma / \beta>1$, so $d \hat{q} / d \gamma=1 /\left(\beta u^{\prime \prime}(\hat{q})\right)<0$. Under condition $1, \bar{k}=\gamma \hat{q} / \beta$.

$$
\frac{d \bar{k}}{d \gamma}=\frac{\hat{q}}{\beta}+\frac{\gamma}{\beta} \frac{d \hat{q}}{d \gamma}=\frac{\hat{q}}{\beta}\left(1-\frac{u^{\prime}}{-\hat{q} u^{\prime \prime}}\right)=\frac{\hat{q}}{\beta}\left(1-\frac{1}{\sigma}\right)<0,
$$


if $\sigma<1$. The cut-off

$$
\frac{d \bar{L}}{d \gamma}=\frac{d L_{2}}{d \gamma}=\frac{\beta k}{\gamma^{2}}\left(\frac{1}{u^{\prime}(\hat{q})}-1\right)<0,
$$

and

$$
\frac{d \bar{\eta}}{d \gamma}=\frac{d}{d \gamma}\left(1-\frac{L}{\frac{\beta}{\gamma} k-u^{-1}\left(\frac{\beta}{\gamma} k\right)}\right)=\frac{L}{\left(L_{2}\right)^{2}} \frac{d L_{2}}{d \gamma}<0 .
$$

Therefore, the size of equilibrium set under condition 1 is smaller if $\gamma$ increases. Under condition $2, \bar{k}=\gamma u(\hat{q}) / \beta$.

$$
\frac{d \bar{k}}{d \gamma}=\frac{\hat{q} u^{\prime}}{\beta}\left(\frac{u}{\hat{q} u^{\prime}}-\frac{u^{\prime}}{-\hat{q} u^{\prime \prime}}\right)=\frac{\hat{q} u^{\prime}}{\beta}\left(\frac{1}{1-\sigma}-\frac{1}{\sigma}\right)<0,
$$

if $\sigma \rightarrow 0$. The cut-off on $\bar{\eta}$ is the same as in condition 1 , hence, $d \bar{\eta} / d \gamma<0$. The cut-off on $L$ is changing according to

$$
\begin{aligned}
\frac{d L_{3}}{d \gamma} & =-\frac{\beta k}{\gamma^{2}}-\frac{1}{\beta u^{\prime \prime}(\hat{q})}=\frac{1}{\beta}\left(-\frac{1}{u^{\prime}(\hat{q})} \frac{\beta k}{\gamma}+\frac{1}{-u^{\prime \prime}(\hat{q})}\right) \\
& \geq \frac{1}{\beta}\left(-\frac{u(\hat{q})}{u^{\prime}(\hat{q})}+\frac{1}{-u^{\prime \prime}(\hat{q})}\right) \\
& =\frac{1}{\beta \hat{q}}\left(-\frac{u}{\hat{q} u^{\prime}}+\frac{u^{\prime}}{-\hat{q} u^{\prime \prime}}\right) \\
& =\frac{1}{\beta \hat{q}}\left(-\frac{1}{1-\sigma}+\frac{1}{\sigma}\right)>0,
\end{aligned}
$$

when $\sigma \rightarrow 0$. Hence, the interval $\left[L_{3}, L_{2}\right]$ is shrinking. Overall, the set of counterfeiting equilibria shrinks as $\gamma$ increases.

\section{A.2 Ex-post Heterogeneity}

In this subsection, we want to highlight the importance of the sequence in producing counterfeits and in the realization of shocks. To do so, we investigate an alternative timing that the decision on counterfeiting happens before the shock is realized. The timing of events in a period is summarized in Figure 5 .

The same idea can be applied to argue that there are at most two submarkets in equilibrium. Given this, the seller's problem at night is the same as in (26) and (27). The expected 


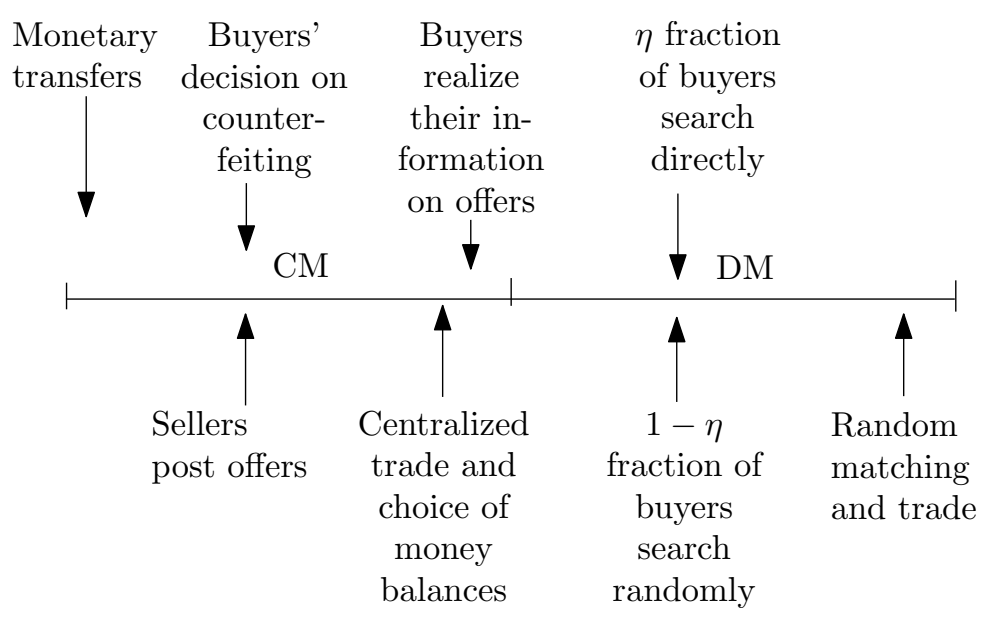

Figure 5: Timing of events in a partially directed search model (ex-post heterogeneity)

surpluses for the genuine buyer are

$$
S^{g}=\max _{\hat{m}} \eta S^{g i}+(1-\eta) S^{g u}-\frac{\gamma-\beta}{\gamma} \phi \hat{m},
$$

where

$$
S^{g i}=\max \left\{\begin{array}{c}
\alpha^{b}\left(\theta\left(q_{l}, d_{l}\right)\right)\left(u\left(q_{l}\right)-\beta \frac{\phi}{\gamma} d_{l}\right) \mathbb{I}_{\left\{d_{l} \leq \hat{m}\right\}}, \\
\alpha^{b}\left(\theta\left(q_{h}, d_{h}\right)\right)\left(u\left(q_{h}\right)-\beta \frac{\phi}{\gamma} d_{h}\right) \mathbb{I}_{\left\{d_{h} \leq \hat{m}\right\}}
\end{array}\right\},
$$

for the informed buyer and

$$
\begin{aligned}
S^{g u}= & \mu \alpha^{b}\left(\theta\left(q_{l}, d_{l}\right)\right)\left(u\left(q_{l}\right)-\beta \frac{\phi}{\gamma} d_{l}\right) \mathbb{I}_{\left\{d_{l} \leq \hat{m}\right\}} \\
& +(1-\mu) \alpha^{b}\left(\theta\left(q_{h}, d_{h}\right)\right)\left(u\left(q_{h}\right)-\beta \frac{\phi}{\gamma} d_{h}\right) \mathbb{I}_{\left\{d_{h} \leq \hat{m}\right\}},
\end{aligned}
$$

for the uninformed buyer taking the distribution of offers as given. The optimal choice of money balances implies that $\hat{m}=\max \left\{d_{l}, d_{h}\right\}$. Otherwise, some submarkets will not be created in equilibrium, because in those submarkets buyers do not have enough money to buy goods. Similarly, the expected surpluses for the counterfeiter are given by

$$
S^{c}=\eta S^{c i}+(1-\eta) S^{c u}-k,
$$

where

$$
S^{c i}=\max \left\{\alpha^{b}\left(\theta\left(q_{l}, d_{l}\right)\right) u\left(q_{l}\right), \alpha^{b}\left(\theta\left(q_{h}, d_{h}\right)\right) u\left(q_{h}\right)\right\},
$$


if the counterfeiter is informed and

$$
S^{c u}=\mu \alpha^{b}\left(\theta\left(q_{l}, d_{l}\right)\right) u\left(q_{l}\right)+(1-\mu) \alpha^{b}\left(\theta\left(q_{h}, d_{h}\right)\right) u\left(q_{h}\right),
$$

if the counterfeiter is uninformed.

The counterfeiting decision is then given by

$$
\max _{p} p S^{g}+(1-p) S^{c}
$$

The market tightness and the beliefs of sellers must satisfy (34), (35), (36) and (37) as well.

Next, we show in Proposition 6 that counterfeiting still cannot occur in this environment. This result is somewhat surprising, but the main intuition still goes back to the refinement concept that makes sellers able to use offers to screen informed buyers and align their incentives. In the current set-up, if counterfeiting happens, some counterfeiters must be informed ex post and direct their search toward sellers. Sellers know this fact and can then actively prevent informed counterfeiters from entering the submarkets, which causes them to have no incentive to produce counterfeits. Since counterfeiters are the same ex ante (i.e., the informed and uninformed counterfeiters must get the same surplus in equilibrium), no one wants to counterfeit bank notes from the beginning.

Proposition 6. Non-existence of counterfeiting.

Proof. If there is one submarket in equilibrium, it must be a low-price market. We can use a similar argument as in the proof of Proposition 1 to show that counterfeiting cannot happen. To see this, suppose there exists a monetary equilibrium with counterfeiting. Consider a deviating offer $\left(q_{l}^{\prime}, d_{l}^{\prime}\right)$ with $q_{l}^{\prime}=q_{l}-\varepsilon$ for an arbitrary small $\varepsilon>0$. Pick $\theta\left(q_{l}^{\prime}, d_{l}^{\prime}\right)=\theta\left(q_{l}, d_{l}\right)$. Then, those informed counterfeiters will not be attracted to this offer. The seller then lowers the payment so that genuine buyers are indifferent between $\left(q_{l}, d_{l}\right)$ and $\left(q_{l}^{\prime}, d_{l}^{\prime}\right)$ as

$$
\begin{aligned}
& \eta \alpha^{b}\left(\theta\left(q_{l}, d_{l}\right)\right)\left(u\left(q_{l}\right)-\beta \frac{\phi}{\gamma} d_{l}\right)-\frac{\gamma-\beta}{\gamma} \phi d_{l} \\
= & \eta \alpha^{b}\left(\theta\left(q_{l}^{\prime}, d_{l}^{\prime}\right)\right)\left(u\left(q_{l}^{\prime}\right)-\beta \frac{\phi}{\gamma} d_{l}^{\prime}\right)-\frac{\gamma-\beta}{\gamma} \phi d_{l}^{\prime} .
\end{aligned}
$$

This requires

$$
d_{l}^{\prime}=d_{l}-\frac{\eta \alpha^{b}\left(\theta\left(q_{l}, d_{l}\right)\right) u^{\prime}\left(\hat{q}_{l}\right) \varepsilon}{\left[1-\frac{\left(1-\eta \alpha^{b}\left(\theta\left(q_{l}, d_{l}\right)\right)\right) \beta}{\gamma}\right] \phi},
$$


where $\hat{q}_{l} \in\left[q_{l}^{\prime}, q_{l}\right]$. Given $\left(q_{l}^{\prime}, d_{l}^{\prime}\right), \delta^{i}\left(q_{l}^{\prime}, d_{l}^{\prime}\right)=1$, informed counterfeiters do not apply for the deviating offer, but informed genuine buyers do. The seller's profit in this submarket is

$$
\begin{aligned}
\alpha^{s}\left(\theta\left(q_{l}, d_{l}\right)\right) & {\left[\eta\left(\beta \frac{\phi}{\gamma} d_{l}^{\prime}-q_{l}^{\prime}\right)+(1-\eta)\left(P \beta \frac{\phi}{\gamma} d_{l}^{\prime}-q_{l}^{\prime}\right)\right]-L } \\
& >\alpha^{s}\left(\theta\left(q_{l}, d_{l}\right)\right)\left(P \beta \frac{\phi}{\gamma} d_{l}-q_{l}\right)-L .
\end{aligned}
$$

The inequality holds if, after plugging $\left(q_{l}^{\prime}, d_{l}^{\prime}\right)$, the following is true:

$$
\beta \frac{\phi}{\gamma}(1-P) \eta d_{l}>\varepsilon\left\{\frac{[\eta+(1-\eta) P] \eta \alpha^{b}\left(\theta\left(q_{l}, d_{l}\right)\right) u^{\prime}\left(\hat{q}_{l}\right)}{\left[1-\frac{\left(1-\eta \alpha^{b}\left(\theta\left(q_{l}, d_{l}\right)\right)\right) \beta}{\gamma}\right] \phi}-1\right\} .
$$

If the bracket on the right-hand side of $(60)$ is negative, then (60) is automatically satisfied for any $\varepsilon>0$. Otherwise, since the left-hand side of 60 is positive and the right-hand side approaches 0 as $\varepsilon \rightarrow 0$, there must exist a $\bar{\varepsilon}$, such that for any $\varepsilon<\bar{\varepsilon}$, (60) holds as well. Hence, the deviating offer contradicts that the original offer is an equilibrium.

If there are two submarkets in equilibrium, we can use the same argument to show that the informed counterfeiters do not enter the low-price market, because if they do, the sellers will have incentives to deviate to earn positive profits, leading to a contradiction. Then, the informed counterfeiters must enter the high-price market. If this is the case, then the sellers who post in the high-price market will deviate to offer lower $q_{h}$ and lower $d_{h}$, so that those informed counterfeiters will not enter at all, but uninformed buyers will still enter. Then, the seller can gain by limiting a smaller fraction of counterfeiters visiting the submarket. This again contradicts the definition of equilibrium.

Overall, in equilibrium, sellers should post offers $\left(q_{j}, d_{j}\right)$ so that $S^{c} \leq S^{g}$ and no one wants to produce counterfeits.

\section{References}

Berentsen, A. And G. Rocheteau, "Money and Information," Review of Economic Studies 71 (December 2004), 915-944.

Cavalcanti, R. And E. Nosal, "Counterfeiting as Private Money in Mechanism Design," Journal of Money, Credit and Banking 43 (October 2011), 625-636. 
Chang, B., "Adverse Selection and Liquidity Distortion in Decentralized Markets," Northwestern University, December 2011.

Chant, J. F., "The Canadian Experience with Counterfeiting," Bank of Canada Review Summer (2004), 41-54.

Delacroix, A. And S. Shi, "Pricing and Signaling with Frictions," University of Toronto, May 2012.

Dong, M. And J. H. JiAng, "Money and Price Posting under Private Information," Bank of Canada Working Paper No. 2011-22, October 2011.

Ennis, H. M., "Search, money, and inflation under private information," Journal of Economic Theory 138 (2008), 101-131.

Faig, M. And B. Jerez, "Inflation, Prices, and Information in Competitive Search," Advances in Macroeconomics 6 (2006), 1-34.

Fung, B. And E. ShaO, "Counterfeit Quality and Verification in a Monetary Exchange," Bank of Canada Working Paper No. 2011-4, 2011a.

— , "Modelling the Counterfeiting of Bank Notes: A Literature Review," Bank of Canada Review Autumn (2011b), 29-35.

Guerrieri, V., R. Shimer and R. Wright, "Adverse Selection in Competitive Search Equilibrium," Econometrica 78 (November 2010), 1823-1862.

Hu, T.-W., "Imperfect recognizability and coexistence of money and higher-return assets," Economic Theory (2011), 1-28.

Lester, B., "Information and Prices with Capacity Constraints," American Economic Review 101 (2011), 1591-1600.

Lester, B., R. Wright And A. Postlewaite, "Information and Liquidity," Journal of Money, Credit and Banking 43 (October 2011), 355-377.

Li, Y. And G. Rocheteau, "Liquidity Constraints," National Taiwan University, November 2009.

—_, "On the Threat of Counterfeiting," Macroeconomic Dynamics 15 (2011), 10-41. 
Li, Y., G. Rocheteau And P.-O. Weill, "Liquidity and the Threat of Fraudulent Assets," Journal of Political Economy 120 (2012), 815-846.

Minm, S., A Nation of Counterfeiters: Capitalists, Con Men, and the Making of the United States (Harvard University Press, 2007).

Nosal, E. And N. Wallace, "A Model of (the threat of) counterfeiting," Journal of Monetary Economics 54 (2007), 994-1001.

Powell, J. AND J. Moxley, "Faking It! A History of Counterfeiting in Canada," Bank of Canada, April 2012.

RCMP Criminal Intelligence, "Counterfeit Currency in Canada," Technical Report, December 2007.

Rocheteau, G. and R. Wright, "Money in Search Equilibrium, in Competitive Equilibrium, and in Competitive Search Equilibrium," Econometrica 73 (2005), 175-202.

ShaO, E., "Money and Barter under Private Information," Contributions in Macroeconomics 9 (2009), 1-35.

U.S. Treasury Department, "The Use and Counterfeiting of United States Currency Abroad," Technical Report, March 2003.

Wallace, N., "The Mechanism-Design Approach to Monetary Theory," in B. M. Friedman and M. Woodford, eds., Handbook of Monetary Economics (Elsevier, 2010), 3-23.

Williamson, S. and R. Wright, "Barter and Monetary Exchange under Private Information," American Economic Review 84 (1994), 104-123. 